\title{
A survey of magnetopause FTEs and associated flow bursts in the polar ionosphere
}

\author{
D. A. Neudegg ${ }^{1}$, S. W. H. Cowley ${ }^{1}$, S. E. Milan ${ }^{1}$, T. K. Yeoman ${ }^{1}$, M. Lester ${ }^{1}$, G. Provan $^{1}$, G. Haerendel ${ }^{2}$, \\ W. Baumjohann ${ }^{2}$, B. Nikutowski ${ }^{3}$, J. Büchner ${ }^{3}$, U. Auster ${ }^{4}$, K.-H. Fornacon ${ }^{4}$, E. Georgescu ${ }^{2,5}$ \\ ${ }^{1}$ Department of Physics and Astronomy, University of Leicester, LE1 7RH, UK \\ ${ }^{2}$ Max-Planck Institut für Extraterrestrische Physik, Garching, Germany \\ ${ }^{3}$ Max-Planck Institut für Aeronomie, Katlenburg-Lindau, Germany \\ ${ }^{4}$ Technische Universität von Braunschweig, Braunschweig, Germany \\ ${ }^{5}$ Institute of Space Science, Bucharest, Romania
}

Receivexd: 6 October 1999 / Revised: 8 December 1999 / Accepted: 13 December 1999

\begin{abstract}
Using the Equator-S spacecraft and SuperDARN HF radars an extensive survey of bursty reconnection at the magnetopause and associated flows in the polar ionosphere has been conducted. Flux transfer event (FTE) signatures were identified in the Equator-S magnetometer data during periods of magnetopause contact in January and February 1998. Assuming the effects of the FTEs propagate to the polar ionosphere as geomagnetic field-aligned-currents and associated Alfvén-waves, appropriate field mappings to the fieldsof-view of SuperDARN radars were performed. The radars observed discrete ionospheric flow channel events (FCEs) of the type previously assumed to be related to pulse reconnection. Such FCEs were associated with $\sim 80 \%$ of the FTEs and the two signatures are shown to be statistically associated with greater than $99 \%$ confidence. Exemplary case studies highlight the nature of the ionospheric flows and their relation to the high latitude convection pattern, the association methodology, and the problems caused by instrument limitations.
\end{abstract}

Key words: Ionosphere (polar ionosphere) Magnetospheric physics (magnetosphere-ionosphere interaction; solar wind-magnetosphere interactions)

\section{Introduction}

A variety of transient high-latitude ionospheric phenomena observed by diverse instruments have been associated with bursty reconnection of the geomagnetic field and the interplanetary magnetic field (IMF) near the magnetopause. These include pulsed auroral phenomena (Sandholt et al., 1985) and associated transient flows (Lockwood et al., 1989; Pinnock et al., 1993). The

Correspondence to: D. A. Neudegg

e-mail: dan2@ion.le.ac.uk association with bursty reconnection has partly been made on the basis of their occurrence under southward IMF $\left(B_{z}<0\right)$ conditions when equatorial magnetopause reconnection is predicted to occur (e.g. Dungey, 1961). The signatures of bursty reconnection at the magnetopause, flux transfer events (FTEs), have also been shown to be statistically related to southward IMF (e.g. Rijnbeek et al., 1984; Berchem and Russell, 1984; Kuo et al., 1995). FTEs and the mechanics of the reconnection process have received much attention, although their nature and cause is still under some debate (e.g. Lockwood and Hapgood, 1998). Nonetheless, observations of FTEs (e.g. Haerendel et al., 1978; Russell and Elphic 1978, 1979; Rijnbeek et al., 1982; Farrugia et al., 1988) and their importance as the signature of transient dayside reconnection have been firmly established (Lockwood et al., 1990, 1993, 1995).

The effect of the transient reconnection is communicated to the ionosphere as an Alfvén wave pulse and associated field-aligned-current (FAC) system (Glassmeier and Stellmacher, 1996; Cowley, 1999). Expected effects of the reconnection-driven FAC system in the ionosphere have been predicted (e.g. Southwood, 1987; McHenry and Clauer, 1987), and include flow velocity bursts, damped ULF wave-trains and transient magnetic field and auroral signatures. The role of transient dayside reconnection in expanding the region of open magnetic flux in the polar cap and subsequently driving the twin-cell convection in the high latitude ionosphere was also examined by Cowley et al. (1991) and Cowley and Lockwood (1992).

HF radars have observed high velocity flow channels in the ionospheric F-region that have been assumed to be the response to transient reconnection (Pinnock et al. 1993, 1995; Rodger and Pinnock 1997). Their spatial extent, flow orientation, MLT occurrence, and dependence on IMF $B_{y}$ have been extensively examined (Provan et al. 1998, 1999; Provan and Yeoman, 1999). The enhanced flow convection channels are observed in the ionospheric region believed to map to the dayside cusp. The cusp and boundary layer, or more generally 
the dayside auroral zone, are believed to be distinguishable by high and varied radar backscatter spectral widths (Baker et al., 1995). The initial observation in the Southern Hemisphere (Pinnock et al., 1993) was of a flow channel zonally aligned, with greater longitudinal extent $(>900 \mathrm{~km}, \sim 3 \mathrm{~h}$ of MLT) than latitudinal $\left(\sim 100 \mathrm{~km}\right.$ or $1^{\circ}$ MLAT) and a poleward turn at the western extremity. Higher temporal and spatial observations of the cusp revealed transients with an average temporal spacing of $7 \mathrm{~min}$ and also occurring nearly simultaneously across $2 \mathrm{~h}$ of MLT (Pinnock et al., 1995). Provan et al. (1998) observed pulsed transients poleward of the convection reversal boundary (CRB) with a recurrence rate of 7-8 min, a longitudinal extent of $1900 \pm 900 \mathrm{~km}$ and a latitudinal extent of $\sim 250 \mathrm{~km}$. The azimuthal components of the plasma flow velocity were $2 \pm 1 \mathrm{~km} \mathrm{~s}^{-1}$ westward, with equatorward speeds of $0.5 \pm 0.25 \mathrm{~km} \mathrm{~s}^{-1}$. The pulsed anti-sunward flow was on open field lines, with a pulsed return sunward flow on closed field lines at lower latitudes. Similar observations have been reported by Milan et al. (1999). Provan and Yeoman (1999) demonstrated that the pulsed ionospheric flows were observed across approximately $12 \mathrm{~h}$ of local time centred in the pre-noon sector but were most likely to be observed in a two hour local time span near 10 MLT. The flows were observed over $75^{\circ}$ to $87^{\circ}$ MLAT but peaked strongly near $80^{\circ}$ MLAT with $70 \%$ having a latitudinal extent of between $3^{\circ}$ and $7^{\circ}$ magnetic latitude. Provan et al. (1999) showed that the statistical location of the pulsed flows is strongly dependent on the IMF $B_{y}$ component, moving into the pre-noon sector in the Northern Hemisphere during intervals of positive $B_{y}$, and into the post-noon sector for intervals of negative $B_{y}$.

A logical progression of magnetosphere-ionosphere coupling investigation is to directly connect FTEs at the magnetopause with the ionospheric flow observations, previously presumed to be caused by transient reconnection. An isolated observation of an FTE near the magnetopause together with spatially limited radar and optical observations of the ionospheric response was published by Elphic et al. (1990) using the best instrumentation available at the time. With the advent of SuperDARN HF radars (Greenwald et al., 1995), it has been possible to image the complete spatial and temporal evolution of the assumed reconnection-related flows within the context of the high-latitude flow patterns. Combined with data from the Equator-S, IMP-8 and WIND spacecraft, it has thus been possible for the first time to make simultaneous observations of the upstream interplanetary medium, transient signatures near the magnetopause, and large-scale flows in the conjugate ionosphere. Neudegg et al. (1999a) used this combination of instrumentation to present a single case study of a southward turning of the IMF, a coincident FTE observed by Equator-S, and the resultant flow channel observed in the conjugate ionosphere by the CUTLASS Finland HF radar.

This work presents several case studies associating the flow channels with flux transfer events under a variety of different conditions, illustrating both their position in the high-latitude ionospheric convection pattern and the flow channel characteristics. An association is then made with a statistically significant sample of events to examine the strength of correlation between these phenomena.

\section{Method}

The requisite conditions for the FTE-FCE association study are;

a. The Equator-S spacecraft must be near the magnetopause, either in the sheath or the magnetosphere, in a position able to observe reconnection signatures if they occur. A limitation of the methodology is the difficulty in judging magnetopause proximity to Equator-S. If the magnetopause, and hence the reconnection region, moves relative to the spacecraft it is difficult to differentiate between when the region has moved out of range of the spacecraft and when reconnection has simply switched off. An example of this limitation will be shown in the third case study. This problem is not a major limitation of the FTE-FCE association as it is possible to use magnetopause crossings as reference points for spacecraft position as well as empirical models of magnetopause location (Roelof and Sibeck, 1993).

b. The spacecraft position must map geomagnetically (Tsyganenko, 1989) to a position in the conjugate northern polar ionosphere, within the field-of-view of at least one SuperDARN HF radar. If the spacecraft is on interplanetary field lines in the magnetosheath then it is required to be in the local time sector of at least one radar on the assumption that the reconnection 'bulge' seen in the sheath will affect the adjacent closed field lines inside the magnetopause. The field-aligned mapping is appropriate because the effect of magnetopause processes are transmitted to the ionosphere as fieldaligned-currents and associated Alfvén-wave patterns (e.g. Glassmeier and Stellmacher, 1996).

c. The radar fields-of-view to which the spacecraft maps must be observing ionospheric scatter, due to the presence of ionospheric irregularities and favourable HF propagation conditions (e.g. Milan et al., 1997, 1998).

To perform a statistical study, the phenomena of interest in each instrument must be represented as an 'event' with certain recognisable characteristics. The reconnection signature represented by a flux transfer event (FTE) is a bipolar excursion in the normal component of the Equator-S magnetometer (MAM) trace (Russell and Elphic, 1978). This requires the data to be transformed from GSE to GSM and then boundary normal (LMN) coordinates (e.g. Russell and Elphic 1978, 1979; Farrugia et al., 1988). We have used an $N$ component normal to a model magnetopause (Roelef and Sibeck, 1993) dependent on upstream conditions. $L$ is tangential to the magnetopause so that the $N-L$ plane contains the $Z$ GSM axis, and $M$ is the westward component mutually orthogonal to $N$ and $L$. The $L$ and $M$ components of the field often exhibit an 
excursion simultaneously with the bipolar signature in $N$. The FTEs identified here were typically of less than five minutes in duration and the peak-to-peak amplitudes in the normal component were 10-60 nT.

The 'flow channel events' (FCEs) observed by the radars in this study were chosen to be regions of high l.o.s. (line-of-sight in a particular radar beam towards or away from the radar) flow velocity (typically $>800 \mathrm{~m} \mathrm{~s}^{-1}$ ), of latitudinal extent $200-500 \mathrm{~km}\left(\sim 2^{\circ}-4^{\circ}\right.$ of latitude) and duration 5-10 min. The flows are usually associated with enhanced backscatter power ( $>15 \mathrm{~dB}$ above background noise) and are within a region of enhanced and widely varying radar spectral width $\left(200-500 \mathrm{~m} \mathrm{~s}^{-1}\right)$ which has been associated with the cusp (Baker et al., 1995).

To perform an unbiased statistical comparison it was necessary to search for FCEs in the radars magnetically conjugate to the spacecraft. Even if the Equator-S magnetometer was not observing FTEs when it was within the typical $1 R_{E}$ FTE scale-size of the magnetopause (Saunders et al., 1984), the conjugate radar data were examined so that each instrument sample was unbiased. Relative onset times were required to associate FCEs with FTEs on a one-to-one basis. The onset times depend on the propagation path of the reconnection effect to each instrument. FTEs seen at Equator-S are presumed to be the signature of the reconnection 'bulge' propagating along the magnetopause from the merging site near the sub-solar point. The effect of reconnection is transmitted to the ionosphere as an Alfvén wave from the reconnection site. The two different propagation paths of order 2-5 min imply the FTE and FCE onsets may not be observed at the same time, and in fact it is possible for the ionospheric FCE signature to be observed first. A difference of 2-3 min was allowed for one-to-one association.

\section{Data selection}

Using the criteria noted, the Equator-S magnetometer and radar line-of-sight data were selected in the following way.

a. Equator-S magnetometer data were available for a total of 142 orbits (corresponding to 136 days or $\sim 4.5$ months) (16 December, 1997-30 April 1998).

b. The orbit precessed anti-clockwise into the dawnside at approximately $1 \mathrm{~h}$ of MLT per month with the initial $11 R_{E}$ apogee located at $\sim 10$ MLT. This allowed magnetopause contact for 64 orbits (61 days) (16 December, 1997-14 February 1998), after which the apogee was inside the flared magnetopause dawn boundary except under unusual conditions.

c. Magnetopause proximity occurred for 38 orbits (36 days), indicated in the magnetometer data by magnetosheath signatures or magnetopause crossings and using orbit predictions for when the spacecraft was within $1 R_{E}$ of an average model magnetopause.

d. The Equator-S location (when in the magnetosphere) or the nearest closed field line region (when in the magnetosheath) geomagnetically maps (via the T89 geomagnetic field model (Tsyganenko, 1989) to at least one Northern Hemisphere radar field-of-view for 30 of those orbits (29 days). This is the subset from which FTE and FCE signatures were drawn.

e. FTEs were observed by Equator-S on 16 of the 29 days in (d).

f. FCEs were observed by SuperDARN on 12 of the 29 days in $(\mathrm{d})$.

\section{Magnetopause region: Equator-S}

Equator-S observed 87 FTEs in the following locations when conjugate with SuperDARN; 65 in the magnetosheath $(75 \%), 20$ in the magnetosphere $(23 \%)$ and 2 on the magnetopause $(2 \%)$. Those in the magnetosheath and on the magnetopause had surrounding $B$ field orientations of $60 \% B_{z}$ southward or near zero and $40 \%$ northward. This ratio of sheath orientations during reconnection is similar to the ratio of IMF orientations observed during pulsed ionospheric flows (Provan and Yeoman, 1999) which is reassuring for associating ionospheric flow transients with bursty reconnection. There is little $B_{y}$ bias in the sampling, which suggests the sample is large enough to have averaged any $B_{y}$ effects out. To examine the IMF dependence, FTE times were lagged by the solar wind speed back to the WIND spacecraft location in the upstream interplanetary medium. Then the WIND magnetometer data (Lepping et al., 1995) were used to determine IMF clock angle. Figure 1a shows the relative clock angle occurrence for the 87 FTEs observed when Equator-S was conjugate with SuperDARN radars. In Fig. 1b clock angle occurrences are shown for the same 87 FTEs normalised by background occurrence of IMF taken at 15 min intervals over a total of $67 \mathrm{~h}$ chosen around the times which the FTEs occur. It can be seen that a southward orientation of the IMF is preferred, as expected, but reconnection can still occur with significant northward fields if the $B_{y}$ component is large enough to take the clock angle southward of a 'wedge' around $B_{z}$ directly northwards. There are uncertainties in the timing, due to assuming that the IMF change propagated from WIND to the magnetopause at a velocity equal to the $x$-component of the solar wind, but the generally $B_{z}$ southward dependence appears similar to that shown in Fig. 10 of Berchem and Russell (1984).

A comprehensive inter-FTE time interval study by Lockwood and Wild (1993) with a much larger data set than our own (341 inter-FTE intervals) found an average value of $8 \mathrm{~min}$ between FTEs in a highly skewed distribution with an upper decile of $1.5 \mathrm{~min}$, a lower decile of $18.5 \mathrm{~min}$ and a mode value of $3 \mathrm{~min}$. We do not wish to emulate this study here but a point of interest on inter-FTE spacing with regards to magnetosphere-ionosphere coupling is the response time of the ionosphere. If the average response time of the ionosphere to the FACs launched from the magnetopause by bursty reconnection events is greater than the average 


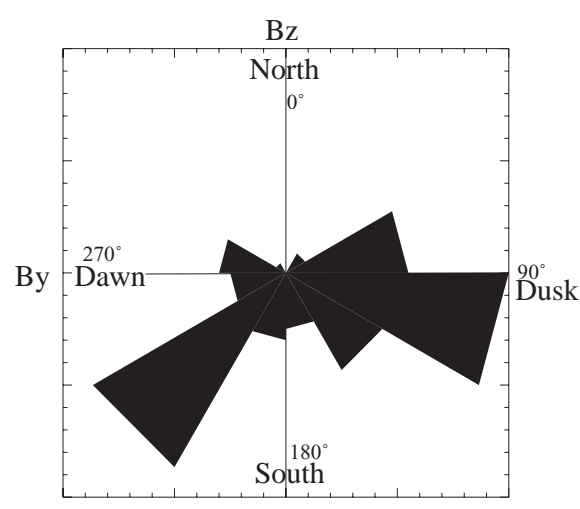

(a)

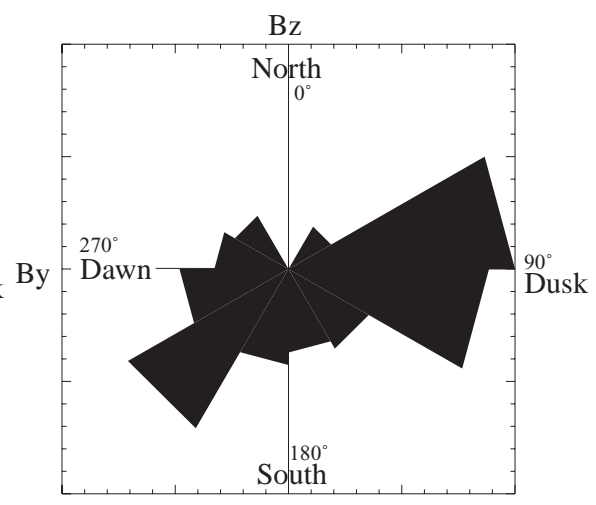

(b)
Fig. 1a, b. IMF clock angles measured by the WIND spacecraft during FTE events measured at Equator-S and time lagged by the solar wind speed from WIND to the magnetopause. a Relative clock angle occurrence for the 87 FTEs observed when Equator-S was conjugate with SuperDARN radars. b Clock angles for the same 87 FTEs normalised by background occurrence of IMF taken at $15 \mathrm{~min}$ intervals over the $67 \mathrm{~h}$ period during which the FTEs occur
inter-FTE interval then the ionospheric response on average will be a convolved series of enhanced flows, making a one-to-one correspondence between individual FTEs and FCE onsets difficult. Our Equator-S data set, constrained by mapping to SuperDARN, had 62 interFTE intervals. If intervals greater than $20 \mathrm{~min}$ (indicating the FTEs were perhaps not part of the same reconnection sequence) were excluded then the average inter-FTE spacing was $8.8 \mathrm{~min}$. In general it appears the FTE probability distribution in this data set is not atypical of that described by Lockwood and Wild (1993).

\section{Polar ionosphere: SuperDARN HF radars}

The SuperDARN HF (8-20 MHz) radar systems have been described in detail by Greenwald et al. (1985). Shown in Fig. 2a from east to west in the Northern Hemisphere are the Finland, Iceland-East, IcelandWest, Goose Bay, Kapuskasing and Saskatoon radars. The system of radars provides wide-area coverage of the polar ionosphere not possible with either VHF or UHF radars. This ability confers a geophysical advantage on the system in allowing it to image large-scale ionospheric flow patterns (e.g. Ruohoniemi et al., 1989). Drawbacks are the multi-hop nature of HF propagation so some regions have ground scatter rather than ionospheric scatter, absorption effects in the $\mathrm{D}$ region ionosphere, and lack of irregularities for the HF signals to scatter from. All these effects reduce the useful ionospheric backscatter to less than the full field-of-view of the radar (e.g. Milan et al., 1997, 1998). Due to the northern inclination of the Equator-S spacecraft orbit, only the six Northern Hemisphere radars were used in this study. Thus the problem of double counting flows in both hemispheres that may be caused by the same FTE was avoided in the statistical study.

The SuperDARN HF radar data were surveyed for FCE signatures during periods of Equator-S magnetopause proximity when the spacecraft was magnetically conjugate with the radar field-of-view. The effects of large FTEs are expected to be viewed by a spacecraft within about $1 R_{E}$ of the magnetopause (Saunders et al.,
1984). Proximity was determined as being within $1 R_{E}$ of a model magnetopause (Roelof and Sibeck, 1993) from orbit data, or within an hour of when the Equator-S magnetometer data indicated a magnetopause crossing. Due to the location of the orbit apogee and the average magnetopause position, these criteria were functionally the same for most of the period. Using the Roelof and Sibeck (1993) model magnetopause catered for periods where the spacecraft was in the sheath during apogee and the only magnetopause crossings observed were entering and exiting the sheath. If the spacecraft was in the magnetosheath, then due to the $11 R_{E}$ apogee it was generally within $1 R_{E}$ of the magnetopause. The extrapolation of the closed field line mapping to the ionosphere at that time was used to determine the expected footprint in the ionosphere of the FTE induced FAC system. Summary spatial plots of radar velocity measurements were surveyed to identify regions of high flow.

The radar spectral width for the high velocity range cells was then examined to determine if the high flow velocities were co-located with regions of high and variable 'cusp-like' spectral widths (Baker et al., 1995) as reconnection-driven flows are expected to lie on open field-lines within the cusp (e.g. Cowley and Lockwood, 1992). All the signatures in this study possessing the characteristics presumed to be associated with reconnection driven flows (e.g. Provan et al., 1998) were found to lie within the region of 'cusp-like' spectralwidth. Baker et al. (1995) demonstrated a clear correlation between the cusp spectral-widths and the DMSP particle signatures associated with the cusp whose sharp equatorward boundary may be expected to coincide with the open-closed field-line boundary (OCFLB). Therefore, for the purposes of this study we use the equatorward boundary of the cusp-like spectral widths as a proxy for the section of the OCFLB where the radars observe scatter. However, the cause of the 'cusplike' spectral widths is not the particle precipitation. Andre et al. (1999) have simulated the spectral width enhancement by the effect of Pc1-2 (0.1-5 Hz) ULF noise activity on the ionospheric plasma velocity and replicated the observed cusp spectral width characteristics. Thus the equatorward boundary of the 'cusp-like' 


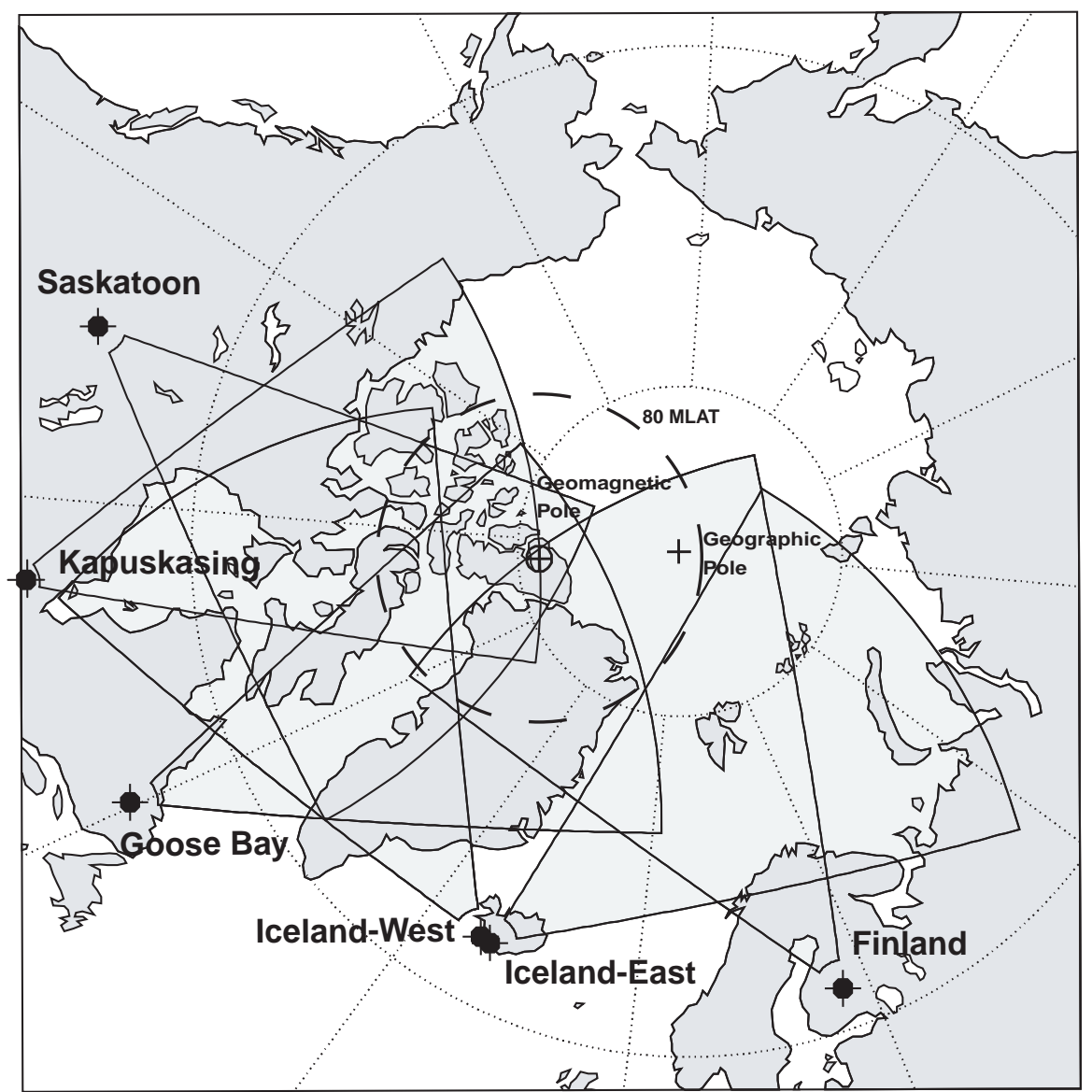

(a)

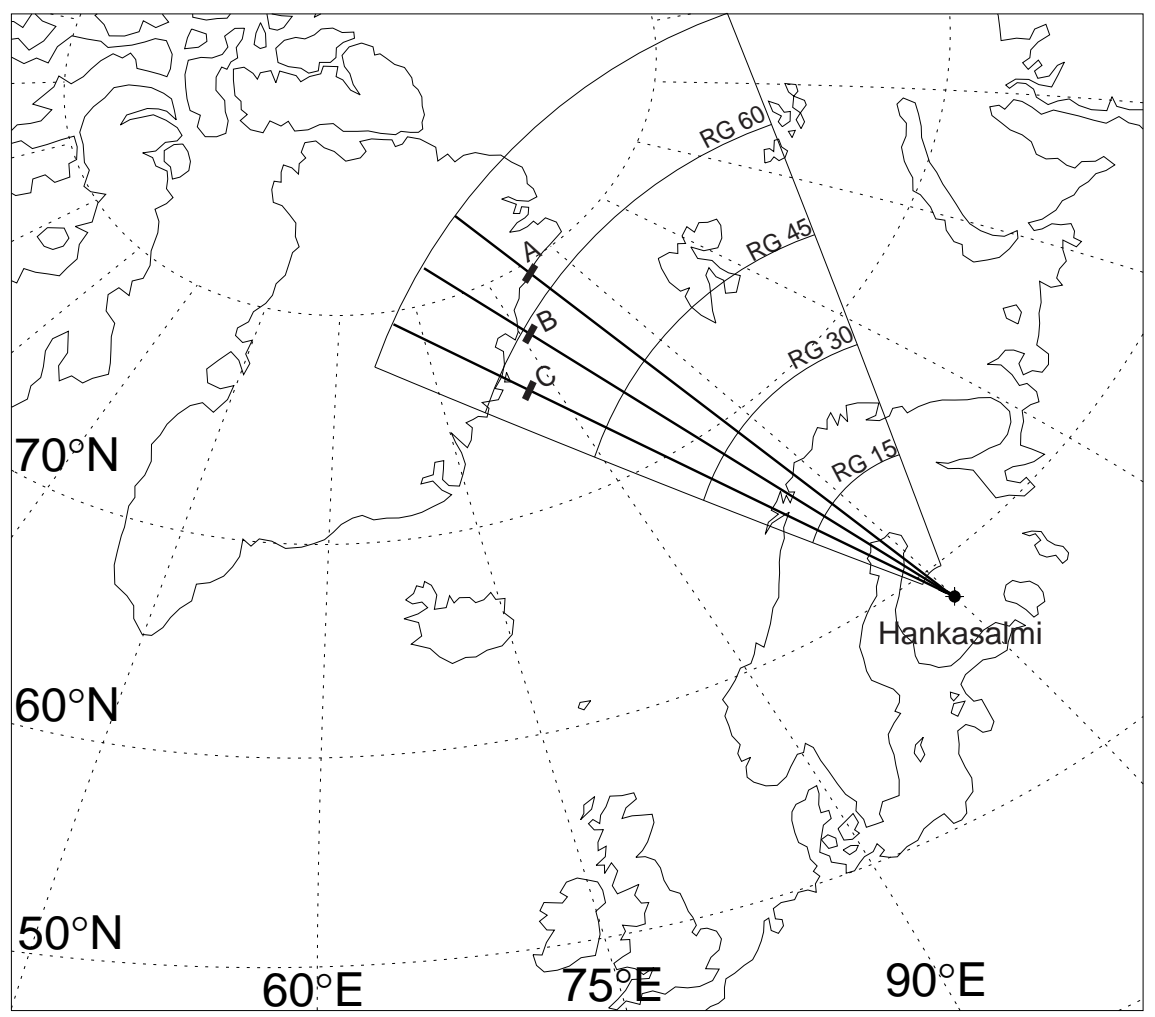

(b)
Fig. 2. a Shows the location and fields-ofview of the Northern Hemisphere SuperDARN HF radars from which data were used in this study. The fields-of-view are using the $45 \mathrm{~km}$ range gates in normal operation. b Shows the field-of-view for the Finland radar for our three case studies using the high spatial resolution scans with $30 \mathrm{~km}$ range gates. The 15 range gate increments are indicated $(R G 15$ etc $)$. The beams and range gates used in our case studies are highlighted. Beam 5, range gate $63\left(80^{\circ} \mathrm{N}\right.$ MLAT, $96^{\circ} \mathrm{E}$ MLONG) for case study a; beam 3 , range gate $59\left(77^{\circ} \mathrm{N}\right.$ MLAT, $90^{\circ} \mathrm{E}$ MLONG) for case b; beam 1 , range gate $55\left(75^{\circ} \mathrm{N} \mathrm{MLAT}, 84^{\circ} \mathrm{E} \mathrm{MLONG}\right)$ for case $\mathrm{c}$. 
spectral widths is possibly the boundary of the waves associated with the cusp. Measurements using a cusp latitude magnetometer array (Neudegg et al., 1995) have shown fast mode waves in the Pc1-2 range propagate away from their near-cusp source in a wave-guide centred on the ionospheric F2 region (e.g. Greifinger and Greifinger, 1968; Fraser, 1975). The waves have a $1 / \mathrm{e}$ folding distance of $310 \pm 220 \mathrm{~km}$ (Neudegg et al., 1999b). These waves may also cause enhanced 'cusplike' spectral widths and therefore some uncertainty exists in the relation between the cusp spectral width boundary observed by HF radar and the 'true' location of the OCFLB.

The individual beams of the geomagnetically conjugate radar observing the FCE most clearly were selected from the full 16 beams to examine FCE temporal evolution by displaying the observed plasma velocity as a function of time and latitude. Onset time of the flow was noted for comparison with FTE occurrence times. Where flow onsets were difficult to resolve from the colour velocity plots, individual velocity time series for specific range gates on that beam were used. In total, 112 flow channel events (FCEs) were observed by the Northern Hemisphere SuperDARN HF radars in the polar ionosphere conjugate to the Equator-S spacecraft during the periods of magnetopause proximity. In the plots of ionospheric plasma l.o.s velocity (both single beam LTV-latitude/time/velocity and full scan plots), ground scatter is shown as grey to illustrate the HF propagation modes and ionospheric returns the radar is observing or missing within its potential field-of-view due to multi-hop propagation. In most cases the ionospheric scatter near the FCE lie at $1 \frac{1}{2} \mathrm{~F}$ or $2 \frac{1}{2} \mathrm{~F}$ multi-hop ranges for the Finland radar plots shown in this work (Milan et al., 1997).

\section{Case studies}

Three case studies are presented here to demonstrate the association of ionospheric FCEs with magnetopause FTEs. The case studies progress through escalating complexity in terms of the number of events, and demonstrate the methodology used in associating individual FTEs and FCEs for the statistical study. All six of the northern radars were used in the statistical study with a large number of events. The three case studies present data from the Finland radar, as the CUTLASS (Finland and Iceland East) systems were run in higher than normal time resolution modes for conjunctions with Equator-S, and quite often presented the highest resolution radar data. Finland radar field-of-view and the beam orientations for beams used in the case studies are shown in Fig. 2b. The range gates selected for best displaying flow onsets in l.o.s. velocities for each of the three cases A, B and C are indicated. A high spatial and temporal resolution scan was run on the Finland radar with $30 \mathrm{~km}$ range gates and a $32 \mathrm{~s}$ scan through the 16 beams. The three cases range from an IMF southward dominated convection pattern, to a moderate $B_{y}$ modulated convection, and then a very $B_{y}$ dominated circulation. The FCEs occur in the dayside region of the two-cell convection pattern where the dayside auroral oval or cusp is situated.

Flow velocity vectors have been constructed for selected periods and superimposed on the scan plots with colour-coded 1.o.s. velocities, using a beam swinging algorithm based on Villain et al. (1987) and Ruohoniemi et al. (1989). The algorithm chooses a number of $L$-shells which cut through the field-of-view of the radar and assumes the flow along these $L$-shells is constant. Knowing the angle of the radar beams to the $L$-shells and the l.o.s. velocity allows a component perpendicular to the radar beams to be estimated. These vectors reveal the velocity structure of enhanced flows and also places them in context of their position within the polarionospheric convection pattern. The large-scale polar ionospheric convection pattern was also constructed using the algorithm described in Ruohoniemi and Baker (1998) based on the statistical model of convection by Ruohoniemi and Greenwald (1996), driven by actual IMF values from the WIND spacecraft. This model takes radar 1.o.s. velocities and then uses a statistical model of radar flows from a historical database based on the IMF values, with spatial and temporal averaging to construct the most likely convection pattern to fit the radar flows. Flow vectors are fitted to measured and modelled velocity information and superimposed on the convection cells. It is prudent to only treat with authority the flows within the convection cells where the radars measured velocities and not fine scale features away from regions of actual radar data. Data from the three case studies will now be described.

\section{a 17 January, 1998}

Figure 3 shows data for a 20 min interval on 17 January, 1998. The top three panels show the IMF $B_{z}$ and $B_{y}$ conditions and the IMF clock angle (degrees clockwise from northward), from the IMP-8 spacecraft located at $\left(X=17, Y=-26, Z=-14 R_{E}\right.$ GSM) suitably time lagged by $6 \mathrm{~min}$ at the solar wind speed to the sub-solar magnetopause position determined by Roelof and Sibeck (1993). The next four panels show the Equator-S magnetometer data in boundary normal coordinates together with the total magnetic field strength. The eighth panel shows plasma l.o.s. velocity measured by the Finland radar in beam 5 (see Fig. 2b) as an LTV plot, and the final panel the 1.o.s. velocity for range gate $63\left(80^{\circ} \mathrm{N}\right.$ MLAT, $96^{\circ} \mathrm{E}$ MLONG, shown as point A on Fig. 2b). Only the Finland radar observed ionospheric scatter as either scatter or HF propagation conditions were not optimal for the Iceland-East radar. The IMF was southward or close to zero and $B_{y}$ was positive. Equator-S was inside the magnetosphere (at position $X=4, Y=-9, Z=4 R_{E} \mathrm{GSM}$ ), within $1 R_{E}$ of apogee. A clear FTE signature can be seen from 0805 UT to 0808 UT, with a typical bipolar excursion of $40 \mathrm{nT}$ peak-to-peak amplitude in the $\mathrm{N}$ component normal to the Roelof and Sibeck (1993) magnetopause. A second 'event' appears to start at 0821 UT but a data 


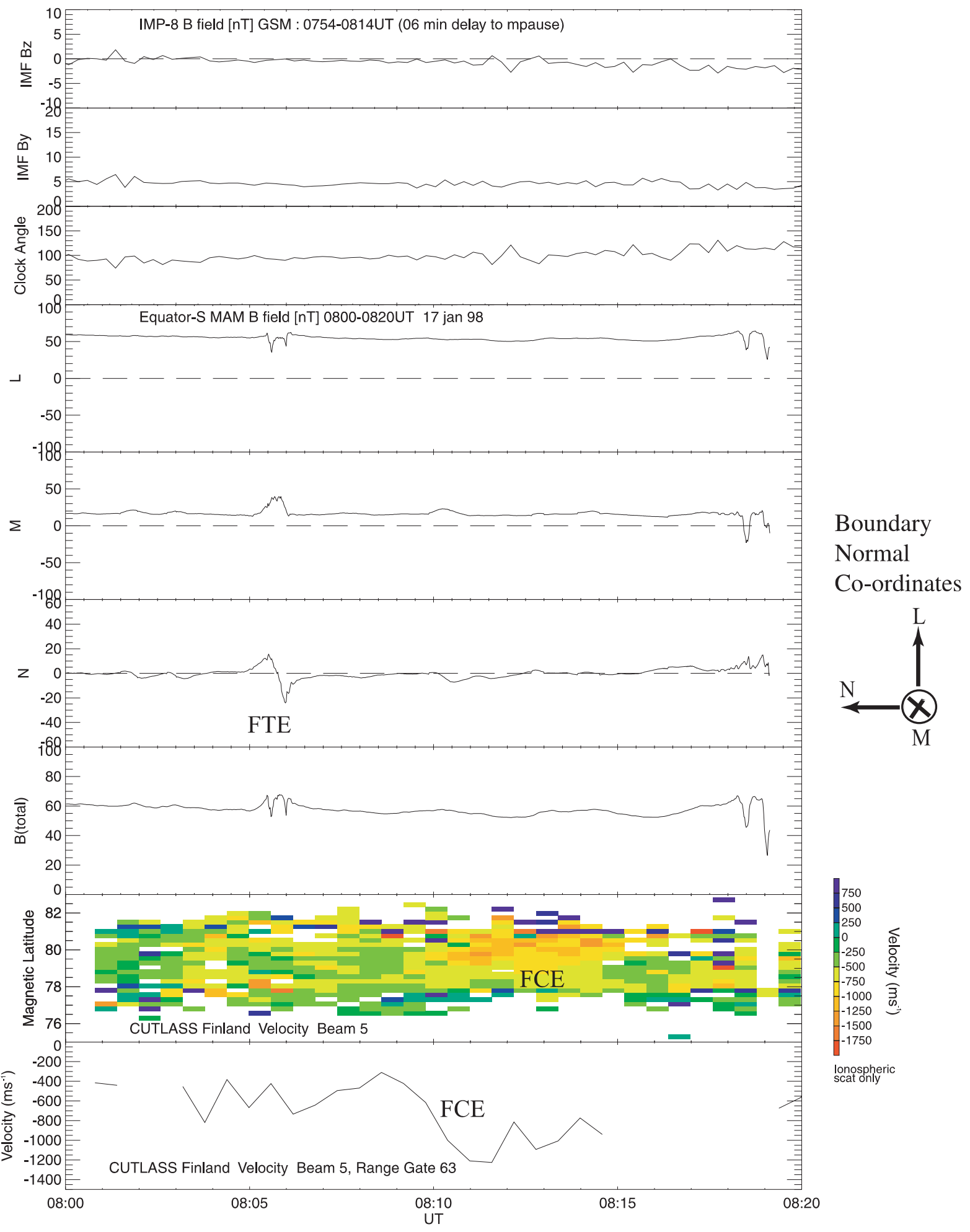

Fig. 3. Case study a, 17 January, 1998, 0800-0820 UT. The first three panels show IMF $B_{z}$ and $B_{y}$ and clock angle conditions for the event from 0754-0814 UT at IMP-8, suitably time lagged by 6 min to 0800 $0820 \mathrm{UT}$ at the sub-solar magnetopause. The next four panels show the Equator-S MAM data in boundary normal coordinates and the total magnetic field. The $N$ component is normal to a model magnetopause, $L$ is tangential to the magnetopause so that the $N-L$ plane contains the Z GSM axis, and $M$ is the westward component mutually orthogonal to $N$ and $L$. The bipolar FTE signature in the $N$ component is indicated. The next panel shows 1.o.s. ionospheric F2 region plasma velocities measured by the Finland radar in beam 5 (see Fig. 2b) as a function of magnetic latitude and UT. The colour bar indicates ionospheric plasma l.o.s. velocity, negative away from the radar and positive toward. The high flow velocity 'flow channel event' $(F C E)$ is indicated. The last panel shows the line-of-sight velocity in beam 5, range gate $63\left(80^{\circ} \mathrm{N}\right.$ MLAT, $96^{\circ} \mathrm{E}$ MLONG - point A in Fig. 2b) as a function of UT with the enhanced flow channel indicated 
gap prevents complete identification. Finland beam 5 shows an FCE signature from 0809 UT to 0816 UT. The measured 1.o.s. velocity in range gate increases from $400 \mathrm{~m} \mathrm{~s}^{-1}$ to $1200 \mathrm{~m} \mathrm{~s}^{-1}$ away from the radar, representative of most of the ranges encompassing the FCE. The pre-noon $(\sim 09-10$ MLT) occurrence of the FCE and the westerly flow in beam 5 (away from the radar, see Fig. 2b) is as expected for IMF $B_{y}>0$ (Provan and Yeoman, 1999).

A series of radar scans with superimposed beamswung velocity vectors during the 0808-0815 UT FCE are shown in Fig. 4 to examine the spatial extent of the FCE. Each panel shows a $32 \mathrm{~s}$ (2 s per beam) scan by the radar with the start time in the top left-hand corner. 12 MLT is at the top of the panel with $1 \mathrm{~h}$ MLT steps toward 18 MLT eastward (left) and 06 MLT westward (right). Latitude intervals of $10^{\circ}$ MLAT are indicated with $80^{\circ}$ MLAT at the lowest arc. Axes markers indicate number of degrees from the invariant geomagnetic pole. Beams are numbered from 0 in the west (right) to 15 in the east (left). Line-of-sight velocities in each range cell are colour coded and the two-dimensional flow vectors derived from the beam-swinging method are superimposed. Figure 4a shows flows during the scan starting at 0808:48 UT, before the onset of the FCE. The ionospheric scatter covers the region 08-13 MLT and $76^{\circ}-82^{\circ}$ MLAT and shows anti-sunward flows of 0 to $600 \mathrm{~m} \mathrm{~s}^{-1}$, away from the radar over the field-ofview, suggesting the dayside region of the twin-cell convection pattern is being imaged. The entire region of ionospheric scatter in the far ranges has 'cusp-like' spectral widths. The rest of the field-of-view comprises ground scatter, sporadic ionospheric returns in isolated range cells or range cells where no scatter was recorded. The FCE has commenced by the 0810:00 UT scan in Fig. $4 \mathrm{~b}$ and 1.o.s. flows greater than $800 \mathrm{~m} \mathrm{~s}^{-1}$ occur in beams 3 to 6 in the far ranges of the central-western field-of-view. The FCE encompasses 9 to 11 MLT $(\sim 750 \mathrm{~km})$ azimuthally and $78^{\circ}-83^{\circ}$ MLAT $(\sim 550 \mathrm{~km})$ latitudinally. The beam-swung velocity vectors show speeds greater than $1 \mathrm{~km} \mathrm{~s}^{-1}$ and directions slightly to the west of the pre-FCE flow. The scan starting at 0811:48 UT in panel c shows the eastward expansion of the region of high l.o.s. velocities $\left(>800 \mathrm{~m} \mathrm{~s}^{-1}\right)$ to cover 9 to 12 MLT $(\sim 1200 \mathrm{~km})$ azimuthally and $78^{\circ}-$ $83^{\circ}$ MLAT $(\sim 550 \mathrm{~km})$ latitudinally, encompassed by beams 2 to 10 . The beam-swung vectors on the eastern edge of the field-of-view show the mainly azimuthal flow in the dusk-cell which turns to polewards in the dayside region of the two-cell convection pattern imaged by the centre and west of the field-of-view. Panel d shows the 0813:00 UT scan where high velocity flows are similar to the previous scan, perhaps slightly reduced in azimuthal extent. The very high beam-swung velocities with eastward tilts in the far ranges may be exaggerations due to limitations in the algorithm although the general flow is oriented eastward. Whether the poleward edge of the ionospheric scatter, which is inside the edge of the

\section{Jan 1998 BEAM SWUNG VECTORS}
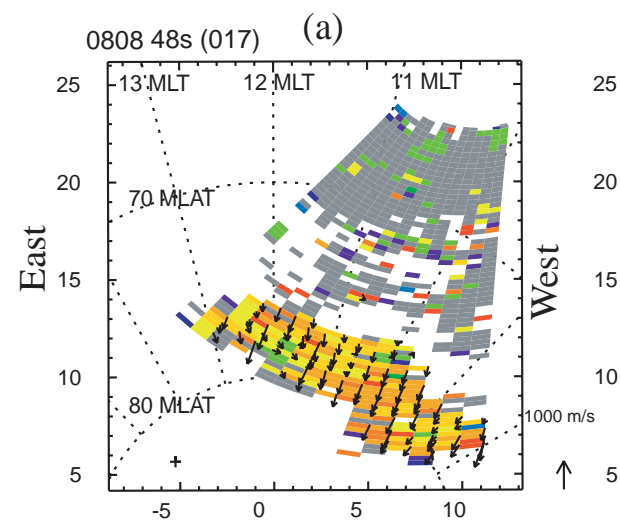

081000 s (017)

(b)
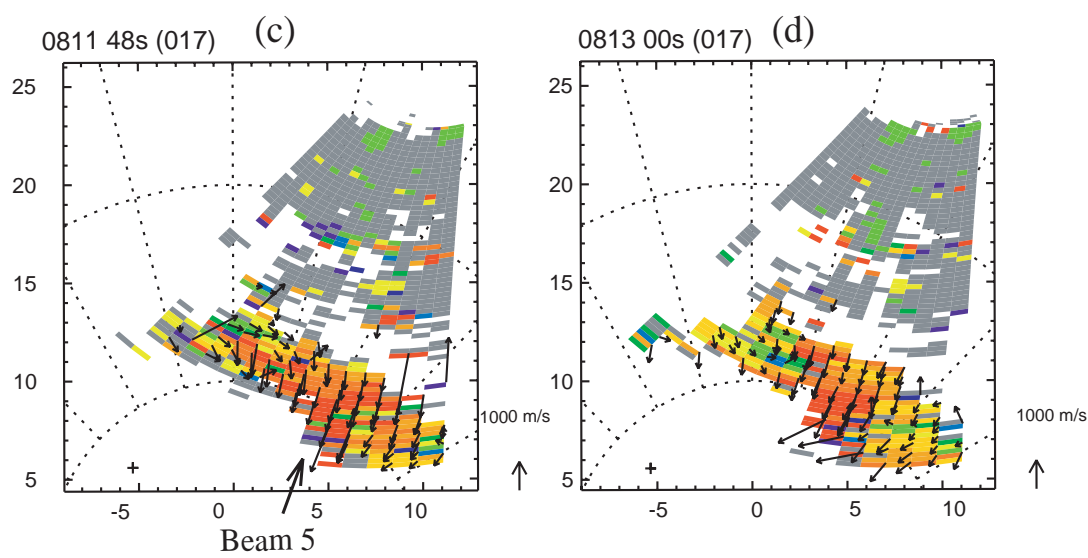

Fig. 4a-d. Case study (a) 17 January, 1998. a shows radar scans slightly before the FCE (0808:48 UT) and b-d during it (0800:00-0813:00). The scans are in geomagnetic coordinates, 12 MLT is at the top of each frame and dawn (west) to the right. Dashed longitude lines are at one hour MLT intervals and circles at $10^{\circ}$ MLAT intervals. The beams are numbered $0-15$ from west (right) to east (left). The FCE region of high flow velocity can be seen in beams 4-6 (RHS) in the far ranges (range gates 50 75) of b-d whilst the near ranges encompass mainly ground scatter. The FCE is the area of high $(>600 \mathrm{~m} / \mathrm{s})$ line-of-sight velocities in the 09-10 MLT sector at $80^{\circ}$ MLAT. The entire ionospheric scatter region had 'cusplike' high and varied spectral widths (not shown) described by Baker et al. (1995). Superimposed are 2-D plasma velocity vectors from the beam-swinging method described in Sect. 2 of the text. See Sect. 3a of the text for further details 
field-of-view, represents a real geophysical boundary is open to conjecture but there is evidence that in some cases the equatorward edge of the 'cusp-like' scatter acts a hard-target for HF radars (Milan et al., 1998). If the scatter boundaries are co-located with geophysical boundaries it is likely that the Finland radar has imaged the entire extent of the enhanced flow channel in this case.

Polar ionospheric convection maps shown in Fig. 5 for the Northern Hemisphere were constructed from radar data for a sequence of scans just prior to the FCE (0808 UT) and during the period of high FCE flow velocities (0812 UT). The grid is MLT and MLAT. Contours of electric potential from a statistical model driven by real WIND IMF values (clock angle shown in the lower r.h.s. icon) are shown solid for negative and dotted for positive values. The contours have been constrained in the region of the Finland radar field-ofview ionospheric scatter by l.o.s. velocity measurements. Superimposed are plasma velocity vectors obtained by combining the measured l.o.s. velocities with the transverse component of the vectors 'fitted' to the potential contours. The order of the fit used was 4 , velocities were only spatially and not temporally filtered, and the maximum uncertainty of the fit $\chi^{2}$ was 1.4 . See (Ruohoniemi and Baker, 1998) for details of the technique. As

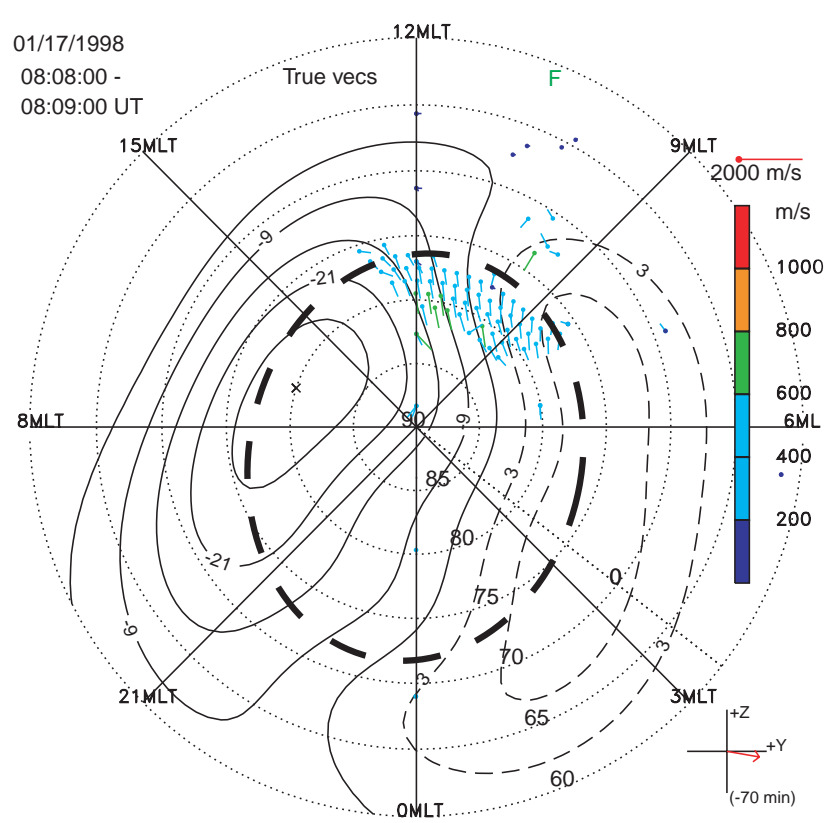

(a)

Fig. 5a, b. Case study (a), 17 January, 1998. Polar ionospheric convection maps using the method of Ruohoniemi and Baker (1998) slightly before the FCE (0808 UT) and during it (0812 UT). The grid is MLT and MLAT. Contours of electric potential from a statistical model driven by real WIND IMF values (clock angle shown in the lower r.h.s. icon) are shown solid for negative and dotted for positive values. The contours have been constrained in the region of the Finland radar field-of-view by measured line-of-sight velocity measurements. Superimposed are plasma velocity vectors obtained by combining the measured line-of-sight velocities with the transverse in Fig. 4 all the ionospheric flow vectors lie within a region of 'cusp-like' spectral widths indicating open field lines. We have also sketched an 'open-closed field-line boundary' (OCFLB) as a dashed line which is compatible with the flow pattern and with the boundary of the observed 'cusp-like' spectral width area, essentially the full region of ionospheric scatter in this case. The enhanced flow vectors are in the 09 to 12 MLT sector from $78^{\circ}$ to $82^{\circ}$ MLAT. According to the ionospheric flow stream lines this is in the dayside region of the twincell convection pattern which accords with the expected cusp position. The enhanced flow occurs in the pre-noon sector, consistent with the findings of Provan et al. (1999) for positive $B_{y}$. A feature of the twin-cell flows shown in all the case studies in this work is a general night-duskside/day-dawnside offset from the noon-midnight MLT meridian orientation to the axis of the convection cells consistent with the findings of Weimer (1995) and Ruohoniemi and Greenwald (1996). The IMF $B_{y}$ orientation then adjusts the dayside highlatitude flows and cusp location in an east-west sense according to the picture of Cowley et al. (1991b).

The picture obtained from examining ionospheric flow patterns is consistent with transient reconnection at the magnetopause creating a localised region of enhanced flow velocity in the cusp region which moves

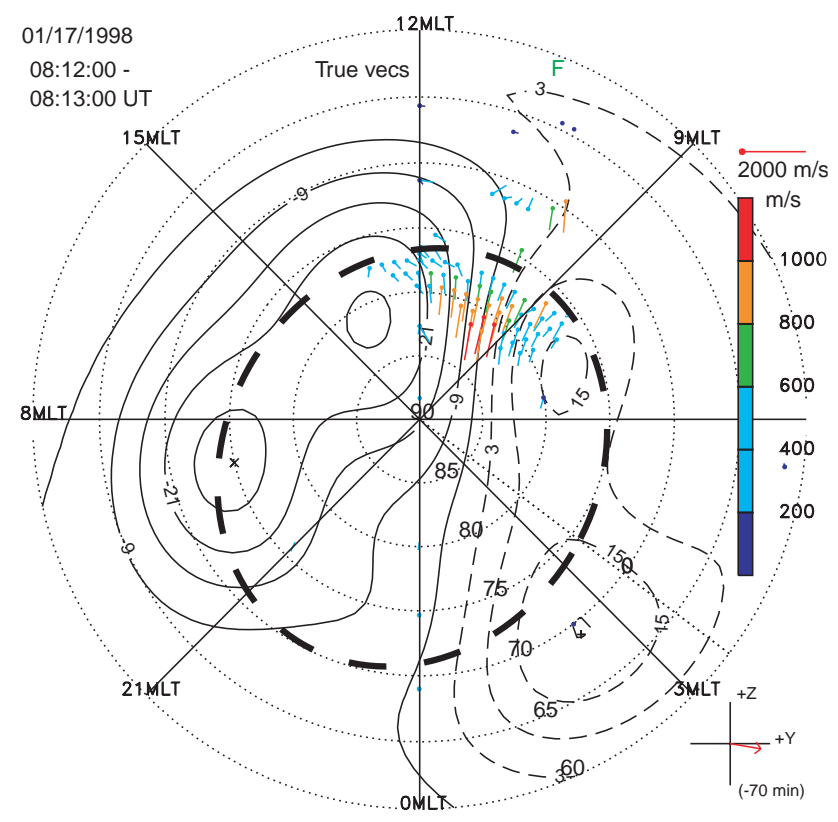

(b)

component of the vectors 'fitted' to the potential contours. The order of the fit used was 4 , velocities were only spatially and not temporally filtered, and the maximum uncertainty of the fit $\chi^{2}$ was 1.4. see Ruohoniemi and Baker (1998) for details of the technique. The enhanced flow vectors can be seen in the 09-10 MLT sector at $80^{\circ}$ MLAT. An extrapolated open-closed field-line boundary (OCFLB) is superimposed and has been fitted to the observed 'cusp-like' spectral width boundary equatorward of the flow vectors. See Sect. 3a in text for further details 
anti-sunward, such that the flow channel appears to impulsively motivate the poleward flows across the cap, contributing to that part of the twin-cell convection pattern. The FCE is close to the poleward edge of the cusp, located in the anti-sunward flows of the dayside region of the convection pattern.

\section{b 4 January, 1998}

The period from 1120 to 1200 UT on 4 January, 1998, shown in Fig. 6 contains a series of FTEs observed in the magnetosheath by Equator-S near the magnetopause, and FCEs observed by the Finland radar. The IMF data from WIND $(X=74, Y=-196, Z=-87$ $R_{E}$ GSM) are shown lagged by 76 min to the sub-solar magnetopause. IMF $B_{z}$ is southward or close to zero for much of the interval whilst $B_{y}$ is steady positive around $5 \mathrm{nT}$. The IMF clock angle at the magnetopause is initially near $50^{\circ}$, not optimal for reconnection. The clock angle changes to $100^{\circ}$, expected to be favourable to reconnection, at $1123 \mathrm{UT}$ and it remains close to $100^{\circ}$ for the period of interest apart from transients during 1131-1135 UT. Equator-S is mostly in the magnetosheath $\left(X=8, Y=-7, Z=4 R_{E} \mathrm{GSM}\right)$, evidenced by the high frequency noise on the traces. A series of bipolar FTE-like disturbances can be seen in the $\mathrm{N}$ component and the more obvious are indicated by arrows. The nearest closed field lines to Equator-S map to the Finland and Iceland East radars which were running in a high time resolution scan in anticipation of conjunctions with the spacecraft. An 1.o.s. velocity LTV plot is shown for Finland beam 3, and the 1.o.s. velocity for range gate $59\left(77^{\circ} \mathrm{N}\right.$ MLAT, $90^{\circ} \mathrm{E}$ MLONG - shown as point $\mathrm{B}$ on Fig. 2b). Iceland East observed mainly ground scatter with a small region of embedded cusplike ionospheric scatter from 1105 to 1140 UT. We will focus on the more comprehensive Finland observations.

From the beam 3 colour LTV plot it can be seen that it is difficult to find an exact one-to-one correspondence between the FTEs and FCE onset times although a general rise in flow velocity with FTE events can be seen. What are believed to be FCE initial onsets are indicated by arrows in the range gate 59 velocities and letters indicate the presumed association with FTEs. There are ambiguities regarding which flow enhancement to associate with which FTE due to unknown time delays between them, but the proposed association seems reasonable and consistent. Comparing onset times in the two phenomena is complicated by the different propagation mechanisms and delays from the assumed reconnection site at the sub-solar magnetopause to the spacecraft and the ionosphere. It is possible for the FAC to propagate to the ionosphere from the reconnection site before the FTE propagates around the magnetopause to Equator-S. Allowing for up to 3 min difference in the propagation times, the typical time of each propagation path, associations can be made between FTEs and FCE onset times illustrating the method for the statistical study. A case can be made that the time difference between the FTE observation at Equator-S due to propagation around the magnetopause and the FCE onset in the ionosphere due to FAC propagation from the reconnection point is relatively insensitive to changes in the position of the reconnection point of a few $R_{E}$ about the sub-solar point. The propagation time of an Alfven wave from the dayside reconnection point to the ionosphere will be constant within one or two minutes for reconnection points between 09 MLT and 15 MLT as the magnetopause stand-off distance is relatively constant across this span. The reconnection bulge travels from the reconnection point around the magnetopause at approximately $400 \mathrm{~km} \cdot \mathrm{s}^{-1}$ (e.g. Sonnerup et al., 1981) and so will cover $3.8 R_{E}$ in one minute. The average inter-FTE timing for events A to E is $5.8 \mathrm{~min}$ so a timing difference of say $3 \mathrm{~min}$ may create some confusion concerning the 'true' sequence of events. The reconnection site would need to move $\sim 11.5 R_{E}$ between reconnection events for there to be significant difference in the inter-FTE-FCE time spacing for successive events. It is unlikely, although not impossible, that the reconnection point would move this far in so short a time if the IMF were relatively quiescent in a southward configuration with only moderately varying $B_{y}$ which were the conditions for most of our sample events. Therefore the assumption of constant time difference, to within two or three minutes, between FTE and FCE onset observation may be used as an aid in associating an FTE with its resultant FCE. A different method is to associate the closest FCE onset in time to a specific FTE. The two methods may produce slightly different associations depending on temporal spacing of the FTEs and the clarity of the ionospheric velocity data. By using a large number of events in a statistical study the subjectivity in the individual FTE-FCE associations is somewhat reduced. In this 4 January case study we have assumed that the reconnection site is at a constant position and FCEs lag the FTEs as for event $\mathrm{A}$, so associations were not made between FTEs and FCEs preceding them, no matter how close in time they were. The velocity responses to FTEs C, D and E appear to merge somewhat with the velocity steadily increasing from 500 to $1000 \mathrm{~m} \mathrm{~s}^{-1}$.

A point to note is that the 76 min delay for the WIND IMF data to the Roelof and Sibeck (1993) model magnetopause was taken from the $X$ components of the solar wind velocity and WIND position and may be in error by several minutes. It is possible that the change in clock angle from $50^{\circ}$ to $100^{\circ}$ corresponding to the $B_{z}$ southward turning at $1006 \mathrm{UT}$, assumed to reach the magnetopause at $1123 \mathrm{UT}$, may correspond with the reduction in the magnetosheath $L$ component at $1130 \mathrm{UT}$ as the sheath field is expected to follow IMF $B_{z}$. This displaces the WIND data by $7 \mathrm{~min}$, which is feasible given the distance of the spacecraft from the magnetopause and its significant $Y$ and $Z$ displacements. It is worth noting that FTE A, signifying the onset of reconnection, then occurs within two minutes of the change in IMF clock angle and the local sheath field indicated by the Equator-S $L$ and $M$ components becoming favourable for reconnection, similar to the prompt response observed by Neudegg et al. (1999a). 


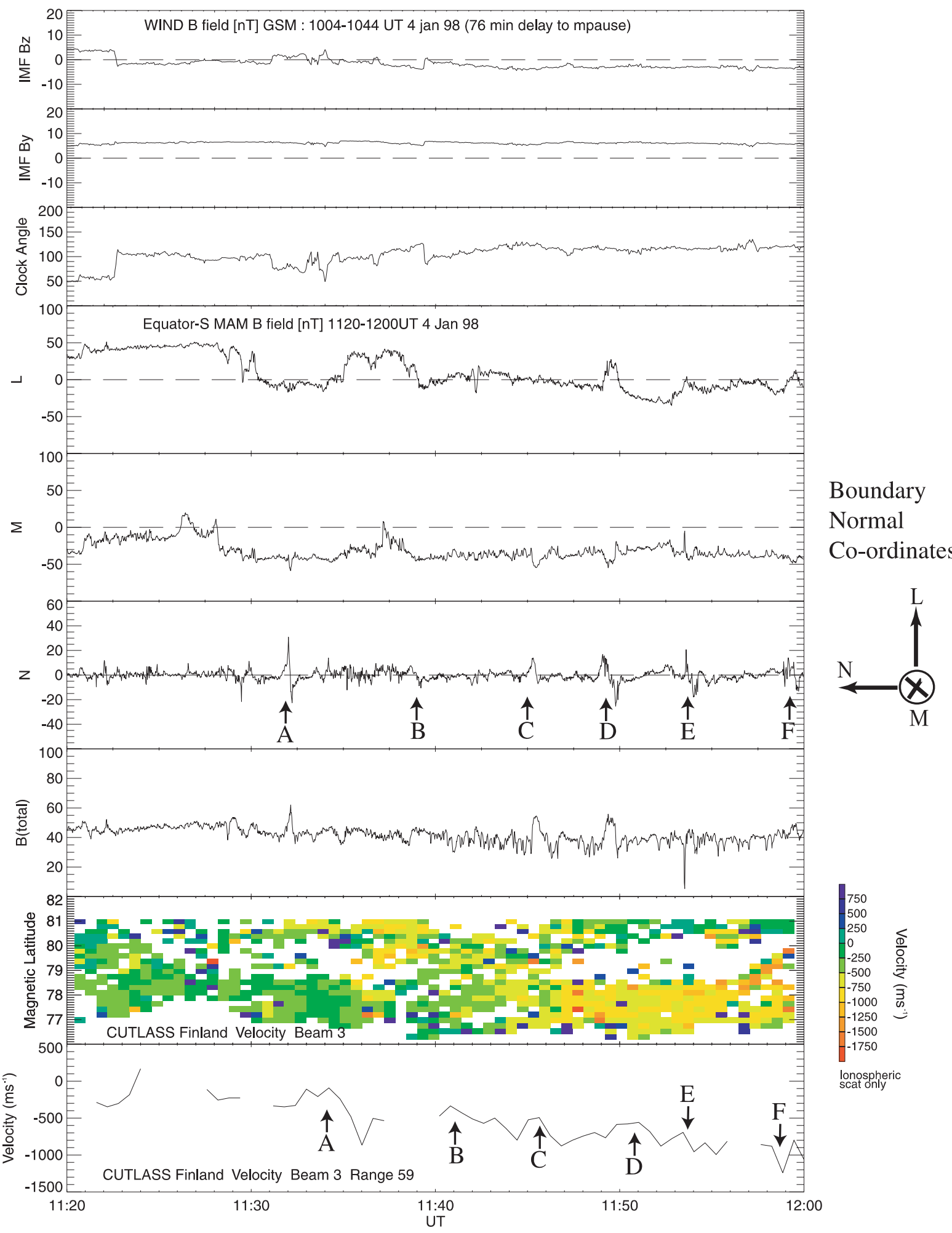

Fig. 6. Case study (b) 4 January, 1998 1120-1200 UT. WIND IMF $B_{z}, B_{y}$ and clock angle, Equator-S magnetic field in LMN coordinates and radar measured ionospheric plasma velocities. See Fig. 3 for general figure format. WIND data from 1004-1044 UT are time lagged by $76 \mathrm{~min}$ to $1120-1200 \mathrm{UT}$ at the sub-solar magnetopause. Equator-S is in the magnetosheath for the entire period. A series of bipolar FTE-like disturbances can be seen in the $N$ component and the more obvious are indicated by arrows. Ionospheric F2 region velocities are shown for Finland beam 3 across $76^{\circ}-82^{\circ}$ MLAT. Lineof-sight velocities from beam 3, range gate $59\left(77^{\circ} \mathrm{N}\right.$ MLAT, $90^{\circ} \mathrm{E}$ MLONG - Point B in Fig. 2b) are shown with the initial onsets of presumed enhanced flow channels associated with the lettered FTEs indicated by arrows 
Figure 7 shows a series of radar scans showing 1.o.s. velocities and superimposed beam-swung flow vectors. The general orientation of the field-of-view, beam numbering, magnetic latitudes and local times are as in Fig. 4. Ionospheric scatter is observed from 11 to 18 MLT and $76^{\circ}$ to $84^{\circ}$ MLAT. Figure $7 \mathrm{a}, \mathrm{b}$ shows $32 \mathrm{~s}$ radar scans commencing at 1142:10 UT and 1142:46 UT during the FCE labelled 'B' in Fig. 6 and Fig. 7c, d scans 1146:23 UT and 1146:59 UT during FCE ' $C$ '. The l.o.s. velocities are low on the eastern side of the field-of-view as flow is westward across the radar according to the beam-swung vectors. Presumably the radar views the westward flows on the equatorward edge of the dusk cell return flow from 14 to 18 MLT in the higher beam numbers. The flow turns poleward where the FCEs occur on the western side of the field-of-view, from 11 to 14 MLT in the lower beam numbers. From FCE $\mathrm{B}$ to $\mathrm{C}$ there is a noticeable increase in the flow velocities within the flow channel and a slight increase in the azimuthal flows in the dusk return cell. Westerly flows agree with that expected for positive IMF $B_{y}$ (Provan and Yeoman, 1999) suggesting the orientation of the twin convection cells also agree with what we would also expect for positive $B_{y}$. The approximate boundary for 'cusp-like' spectral width is indicated and appears to coincide with the transition from the dusk cell return flow to the dayside cusp. The boundary appears to expand slightly equatorward or back along the return flow streamlines with time. Presumably the region of open magnetic flux expands (Cowley and Lockwood, 1992) as reconnection occurs and the flow channels bring open flux into the polar cap.

The convection maps in Fig. 8 are constructed using data from the Finland, Iceland-West, Kapuskasing and Saskatoon radars. Figure 8a is the flow over the scans during the 1142 to 1144 UT period during FCE B and Fig. $8 \mathrm{~b}$ is over 1146 to 1148 UT during FCE C. Thus Fig. 8a may be compared with Fig. 7a, b and Fig. 8b may be compared with Fig. 7c, d. The order of the fit used was 4 , velocities were only spatially and not temporally filtered, and the maximum uncertainty of the fit $\chi^{2}$ was 0.8 , see Ruohoniemi and Baker (1998) for details of the technique. The maps show enhanced flows occur on the dayside edge of the dusk convection cell near 12 to 14 MLT which is somewhat duskward of the narrow 'throat' of the convection pattern. As the cusp spectral width boundary is 'behind' the FCEs in the sense of flow, it appears the dayside edge of the dusk-cell is part of the cusp and the 'merging gap' is at least partly in the post-noon sector rather than just across the narrow 'throat' region at 9 MLT. This picture of postnoon displacement for the cusp is consistent with that predicted for positive $B_{y}$ by Cowley et al. (1991) (Fig. 1). However, it should be noted that this example shows the location of the ionospheric reconnection signature within the convection pattern and the overall

\section{Jan 1998 BEAM SWUNG VECTORS}
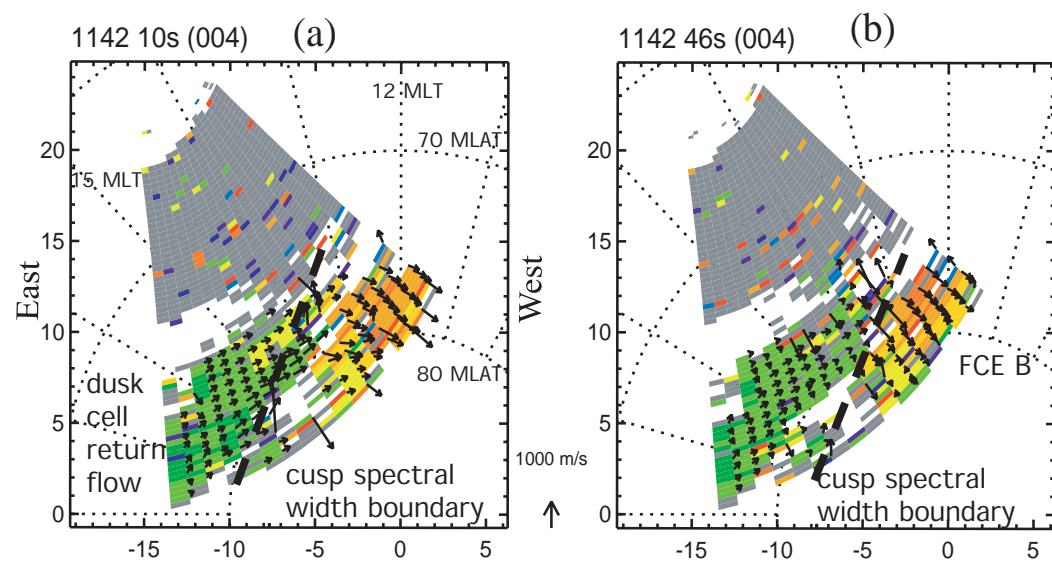

(c)

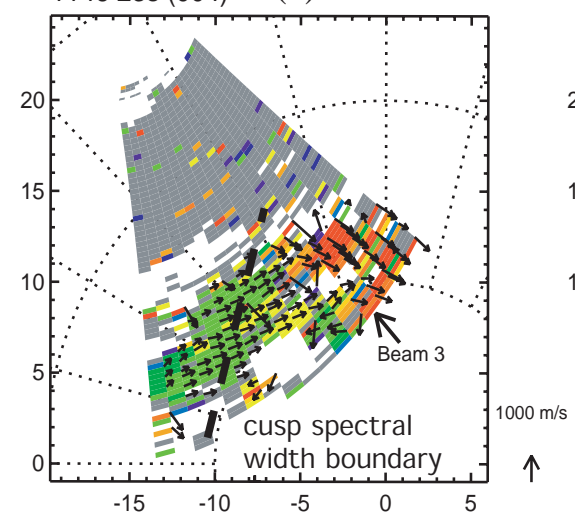

$114659 \mathrm{~s}(004)$

(d)

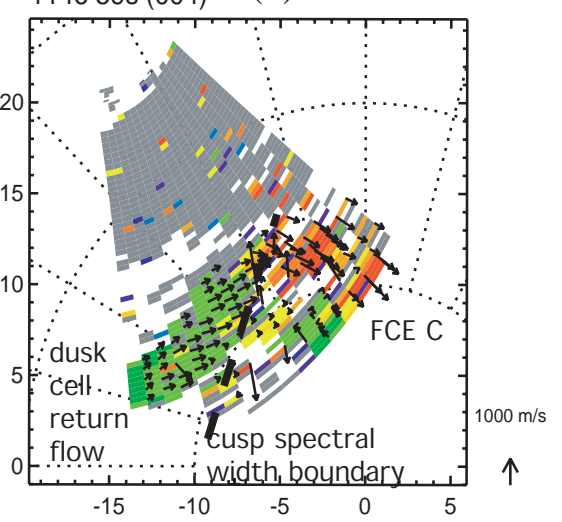

Fig. 7a-d. Case study (b) 4 January, 1998. Scans for the Finland radar showing line-of-sight velocities and beam-swung 2-D velocity vectors in the same format as Fig. 4. The scans in a and $\mathbf{b}$ cover the times when FCE B (see Fig. 6) occurs and $\mathbf{c}$ and $\mathbf{d}$ show FCE C. The predominantly azimuthal flow in the high beam numbers (eastern edge - 1.h.s.) is presumed to be part of the dusk convection cell return flow. The FCEs are represented by the high line-of-sight velocities $(-400$ to $-800 \mathrm{~m} \mathrm{~s}^{-1}$ ) away from the radar on the western (r.h.s) edge. The equatorward boundary of the 'cusp-like' spectral widths are shown by the dashed line in all scans. The FCEs and region of predominantly poleward flow on the western edge have 'cusp-like' spectral widths and are presumed to be the cusp region of the convection cell. See Sect. $3 b$ in text for further details 


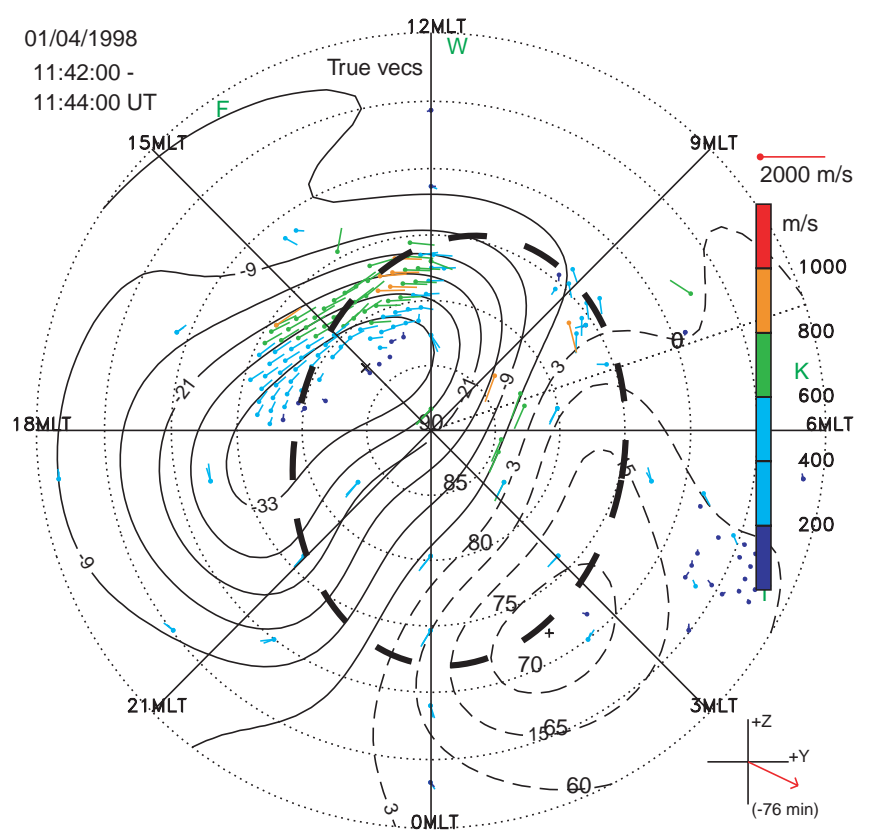

(a)

Fig. 8a, b. Case study (b) 4 January, 1998. Convection maps using the method of Ruohoniemi and Baker (1998). a is 1142 to 1144 UT covering the response to FTE B in Fig. 6. b is 1146 to 1148 UT covering the response to FTE $\mathrm{C}$. The format is the same as Fig. 5. The contours have been constrained by Finland, Iceland-West, Kapuskasing and Saskatoon measured data. Most of the ionospheric returns occur in the Finland radar. The order of the fit used was 4, velocities were only spatially and not temporally filtered, and the maximum

shape of the pattern may exhibit more variation than the theoretical predictions suggest. An OCFLB has again been sketched, consistent with the twin-cell pattern and the observed cusp spectral width boundary. The observations are again consistent with the thesis of the flow channels driving the polar-cap flow in the twin-cell pattern.

\section{c 7 January, 1998}

The FTE-FCE series during a 40 min interval on 7 January, 1998, is shown in Fig. 9, and illustrates a case where the rate of reconnection events at the magnetopause is higher than previous examples. The IMF data from IMP-8 ( $\left.X=19, Y=-24, Z=11 R_{E} \mathrm{GSM}\right)$ has been time-lagged by $3 \mathrm{~min}$ to the sub-solar magnetopause. IMF $B_{z}$ is initially slightly southward turning to moderately northward near 11 UT at the magnetopause. $B_{y}$ is very strongly positive at +18 to $+14 \mathrm{nT}$. The IMF clock angle changes smoothly from $95^{\circ}$ to $70^{\circ}$ over the interval and allows reconnection to occur, even though the field is northward when FTEs are observed. Equator-S $\left(X=8, Y=-4, Z=4 R_{E}\right.$ GSM, $\sim 10$ MLT) is in the magnetosheath, five hours after apogee. The spacecraft was at the same $X$ distance and $3 R_{E}$ in $Y$ from apogee, approximately $2 R_{E}$ inside a quiescent Roelof and Sibeck (1993) model magnetopause so the

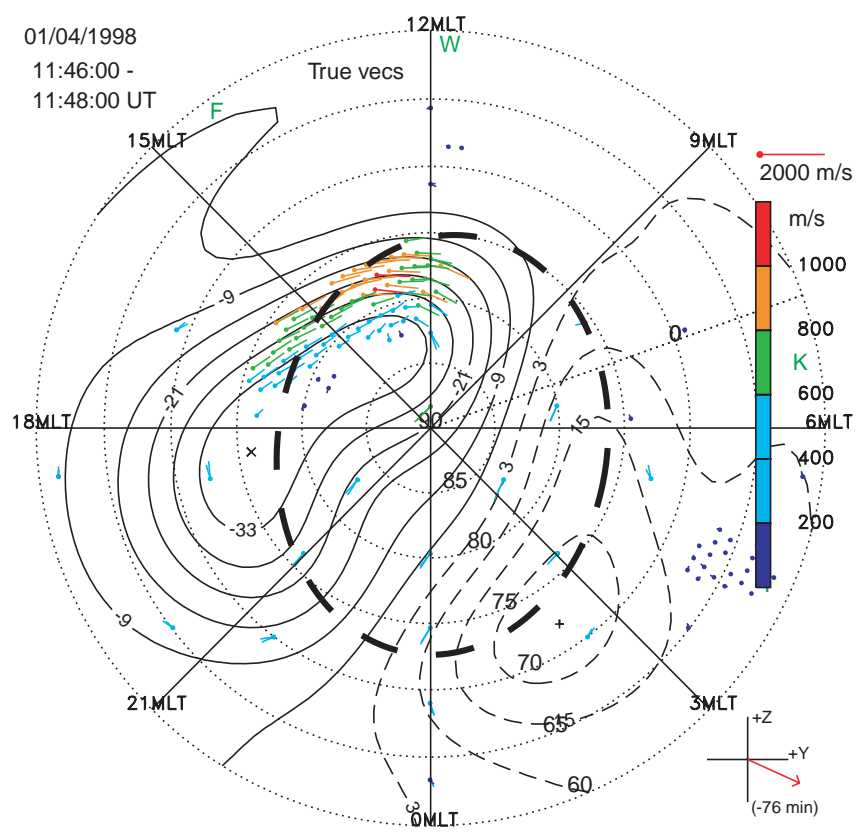

(b)

uncertainty of the fit $\chi^{2}$ was 0.8 , see Ruohoniemi and Baker (1998) for details of the technique. The convection pattern is twin-cell IMF $B_{z}$ southward although $B_{y}$ positive dominated. An extrapolated openclosed field-line boundary (OCFLB) is superimposed and has been fitted to the cusp spectral width boundary passing through the flow vectors near the edge of the dusk cell return flow. The high flow velocity region associated with the FCEs is in the cusp. See Sect. 3b in text for further details

magnetopause was closer to Earth than its average position. An FTE series (A to D) is observed from 1100 UT to 1108 UT and the more obvious examples are marked. There is a partial boundary layer/magnetopause encounter from 1103 to 1107 UT coinciding with a rapid succession of FTEs labelled 'B' during 1103 to $1105 \mathrm{UT}$, presumably related to the lower amplitude and higher frequency reconnection fine structure close to the boundary layer (BL). The FTEs are spaced by as little as one minute, which has implications for flow responses in the ionosphere, which will not be able to respond on so short a time scale. From 1108 to 1116 UT (after FTE D) the spacecraft is again in the sheath with similar field orientations to that at the time of FTE A. Equator-S observes what appear to be the far-field observations of large FTEs between the spacecraft and the magnetopause, rounded in appearance due to observation of only their low frequency components. As the spacecraft gets closer to magnetopause another fully formed FTE (E) is observed. A boundary layer transit occurs from 1116 UT to $1118 \mathrm{UT}$, the spacecraft enters the magnetosphere from 1118 UT to 1127 UT where no FTEs are observed, returns through the boundary layer $1127-1128$ UT and observes another FTE (F) almost immediately upon returning to the magnetosheath. The magnetosphere entry period can be seen as a positive excursion in the $L$ component, an increase from negative values to zero in 


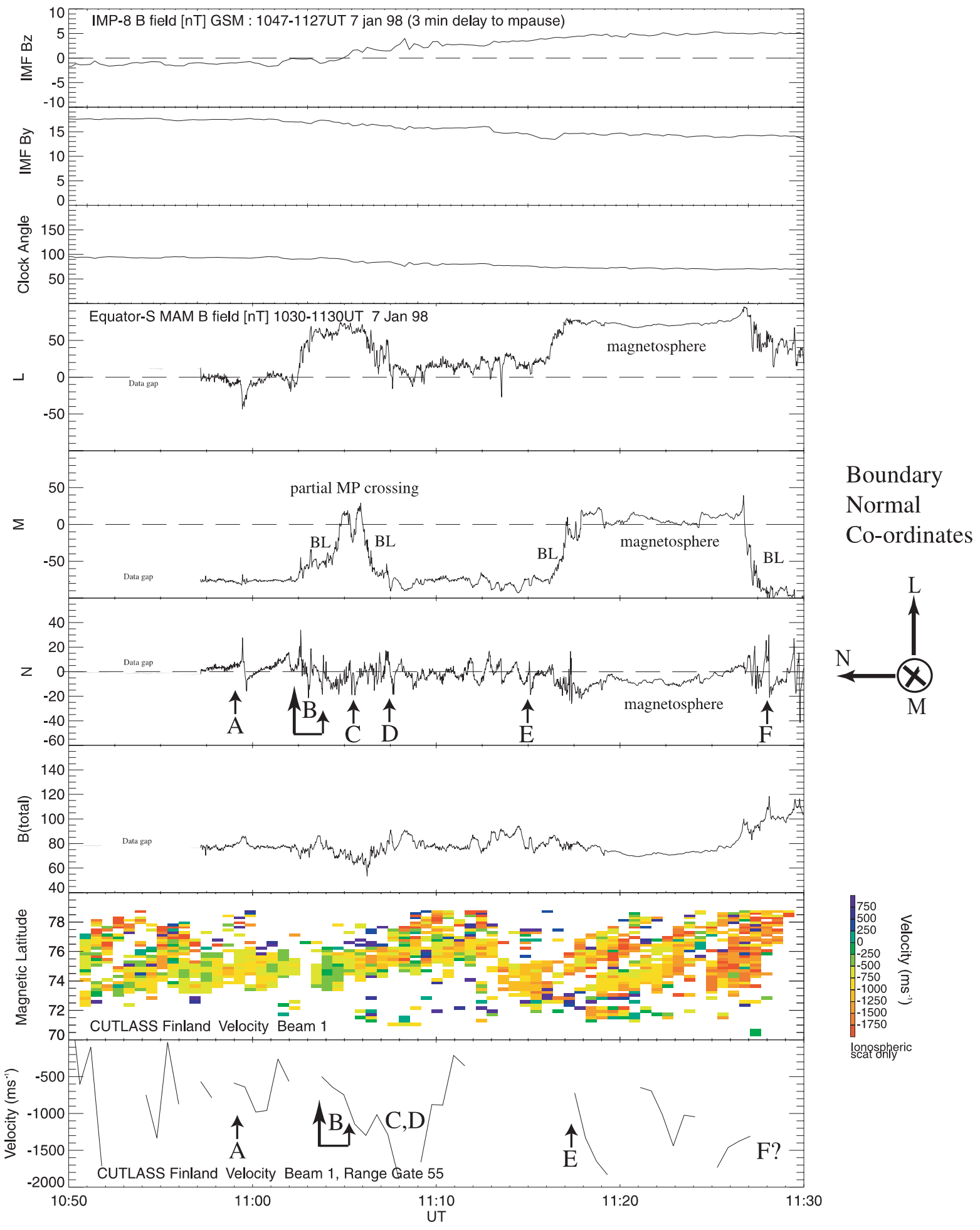

Fig. 9. Case (c), 7 January, 1998 1050-1130 UT. IMP-8 IMF $B_{z}, B_{y}$ and clock angle, Equator-S magnetic field in LMN coordinates and radar measured ionospheric plasma velocities in the same format as Fig. 3. IMP-8 IMF for 1047-1127 UT was time lagged by 3 min to 1050-1130 UT at the sub-solar magnetopause. The northward $B_{z}$ (after $1105 \mathrm{UT}$ ) and high positive $B_{y}$ are to be noted. The IMF clock angle alters slowly from $95^{\circ}$ to $50^{\circ}$. Equator-S was in the sheath initially and prominent FTEs are highlighted in the $N$ component. A 'classic' FTE signature (FTE $A)$ is observed at 1059 UT. The spacecraft encounters the boundary layer $(B L)$ twice in a partial magnetopause/boundary layer crossing from 1104 to 1108 UT where several FTEs ( $B, C$ and $D$ ) occur. From 1108 to 1116 UT Equator-S observes only one FTE $(E)$ after a series of possibly far-field reconnection signatures. It enters magnetosphere proper from 1120 1128 UT with BL crossings either side and then observes another FTE $(F)$ upon re-entering the magnetosheath. Finland radar lineof-sight ionospheric $\mathrm{F} 2$ region plasma velocities from beam 1 are shown in the next panel from $70^{\circ}-80^{\circ}$ MLAT. The last panel shows lineof-sight velocities in beam 1 , range gate $55\left(75^{\circ} \mathrm{N}\right.$ MLAT, $84^{\circ} \mathrm{E}$ MLONG - Point C in Fig. 2b) with the initial onsets of flow enhancements associated with the FTEs indicated by arrows. See Sect. $3(\mathrm{c})$ of the text for further details 
the $M$ component, and a lack of high frequency noise in all components. The closest closed field lines to the spacecraft were conjugate with the Finland radar. An 1.o.s. velocity LTV plot for beam 1 and a line plot for range gate $55\left(75^{\circ} \mathrm{N}\right.$ MLAT, $84^{\circ} \mathrm{E}$ MLONG - shown as point $\mathrm{C}$ in Fig. 1b) are shown in Fig. 9, as flow channels were observed on the western edge of the field-of-view. The initial onsets of the more prominent FCEs are labelled to associate them with the FTEs. The group B FTEs have been associated with the onset of a single flow enhancement near 1103 UT. The flow channel scatter has the characteristic high and varied 'cusp-like' spectral widths (not shown) associated with dayside auroral zone as in previous examples. The pre-noon MLT occurrence of the flows and their westerly (away from the radar) direction agree with that expected for positive $B_{y}$ (Provan et al., 1999). The flow channels continue to be observed in the ionosphere when Equator-S moves into the magnetosphere from 1118 to 1127 UT. The reconnection site may move away from the spacecraft but still map to the same region of ionosphere, as the feet of the field lines will not move far in the incompressible fluid.

This FTE/FCE series highlights the difficulty in finding a one-to-one association between individual FTEs and FCEs when events are closely spaced. It appears that where FTEs are closely spaced in time, the first initiates an enhanced flow velocity in the ionosphere, which may slightly diminish before the next FTE drives the velocity higher again. From observation, if the FTEs are spaced by less than approximately 5 min then the ionospheric responses appear to merge, as expected theoretically (Cowley, 1998). As stated in the methods section the average inter-FTE interval was $8.8 \mathrm{~min}$. An average inter-FTE spacing of considerably larger than the ionospheric response time of 5 min suggests that usually it is possible to resolve the ionospheric flow response to an individual FTE if it is one of a sequence. $35 \%$ (22) of the inter-FTE intervals were less than $5 \mathrm{~min}$ in duration. Therefore a significant number of FTEFCE associations (perhaps $\sim 30 \%$ ) would be affected by the convolution of ionospheric responses. However, FCE onsets can be detected in the radar flow velocities even if FCE spacing is less than 5 min and the flow does not fully recover to background levels as the flow onset is usually a sharp response in the velocity response at a particular range gate. Establishing a one-to-one correspondence between FTEs spaced by less than $5 \mathrm{~min}$ and resultant FCE onset times in an extended statistical study is not as difficult as might be first expected from surveying colour LTV plots or a sequence of scans. Detailed studies of the probability distributions for reconnection related ionospheric flows have been presented by Provan and Yeoman (1999) and McWilliams et al. (2000).

A series of beam-swung velocity scans for the Finland radar are shown in Fig. 10 with a similar general format to Figs. 4 and 7. Figure 10a, b shows the scans beginning at 1105:39 UT and 1106:15 UT, imaging flows associated with the group B FTEs in Fig. 9. Figure 10c, d shows the 1108:03 UT and 1108:39 UT scans associated with FTE C. There are two main areas of ionospheric scatter to be considered with 'cusp-like' spectral widths, region 1 from 1230 to 1430 MLT and $71^{\circ}$ to $75^{\circ}$ MLAT surrounded by a region of ground scatter, and region 2 from 1130 to $1300 \mathrm{UT}$ and $75^{\circ}$ to $78^{\circ}$ MLAT. The flow channels extend across both regions and their distinct boundaries may be an HF propagation effect. However, the lack of ionospheric scatter between the two regions and the possible geophysical nature of scatter boundaries (Milan et al., 1998) suggest the regions may also represent distinct geophysical features. The scatter in the close ranges is equatorward of the 'cusp-like' spectral width boundary and will not be considered here. The spectral width boundary is shown on each scan, coinciding with the equatorward edge of the region 1 scatter. The enhanced flows associated with FTE group B in Fig. 10a, b are generally north and west in region 1 and variable east-west in region 2 with speeds of 600 to $1000 \mathrm{~m} \mathrm{~s}^{-1}$. The westward flow in the noon MLT sector for strongly positive IMF $B_{y}$ agrees with the observations of Provan and Yeoman (1999). The flow speeds increase in region 2 to over $1000 \mathrm{~m} \mathrm{~s}^{-1}$ and the flow becomes divergent. The flows speeds associated with FTE C in Fig. 10c, d are greater than the previous two panels as the flows generally increase due to the closely spaced FTE sequence, as shown by beam 1, range gate 55 1.o.s. velocities in Fig. 9. The flows are again westward in region 1 but this time exceed $1000 \mathrm{~m} \mathrm{~s}^{-1}$. In region 2 the flows generally continue westward and again increases in magnitude, in some cases to $2000 \mathrm{~m} \mathrm{~s}^{-1}$. The flows in the far ranges of region 2 appear to become variable east-west in nature.

Figure 11 shows rare two radar observations, in this case Finland and Iceland-West, of flow channels from 1104-1116 UT. The method of Ruohoniemi and Baker (1998) has again been used to put ionospheric plasma flow velocity observations into the context of the polar ionospheric potential and convection patterns. The order of the fit used was 4, velocities were only spatially and not temporally filtered. The uncertainties for the fit $\chi^{2}$ ranged from 1.9 to 2.6 , higher than normal but understandable insofar as the strong IMF $B_{y}$ causes an unusual orientation for the convection cells and difficulties with the fitting. The extremely strong IMF $B_{y}$ has distorted the twin-cell convection pattern in the manner predicted (e.g. Cowley and Lockwood, 1992) with the open 'throat' of the pattern oriented towards the postnoon sector and westward flows near noon MLT, agreeing with the observations of Provan et al., (1999). Figure 11a shows the background flows before the effect of FTE group B and Fig. 11b-f shows the development of the flows resulting from FTEs B, C and D. The Iceland-West scatter is not extensive but some enhanced flow vectors are observed to help define the azimuthal extent of the FCE radar targets. Data are also used from the Kapuskasing and Saskatoon radars to constrain the convection-cells although the area of scatter is small due to unfavourable HF propagation conditions and/or lack of ionospheric backscatter targets. The boundary of 'cusp-like' spectral widths near $\sim 72^{\circ}$ MLAT is shown with an extrapolated OCFLB. The flow channels are 


\section{Jan 1998 вeamswung vectops}
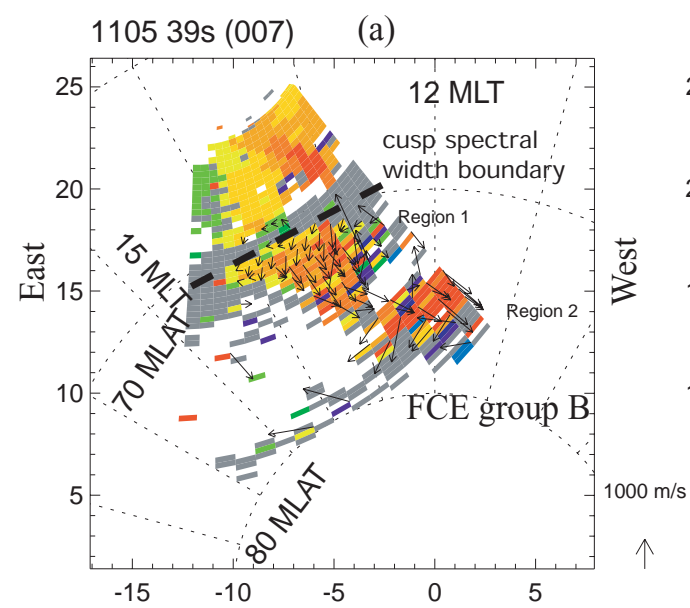

110615 s (007)

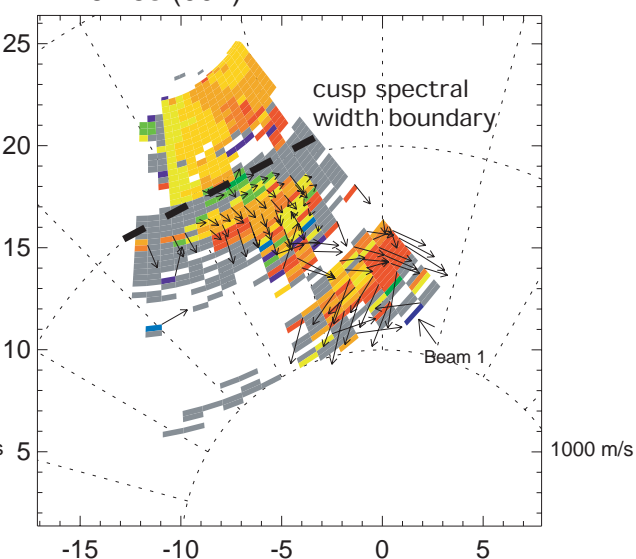

(c)
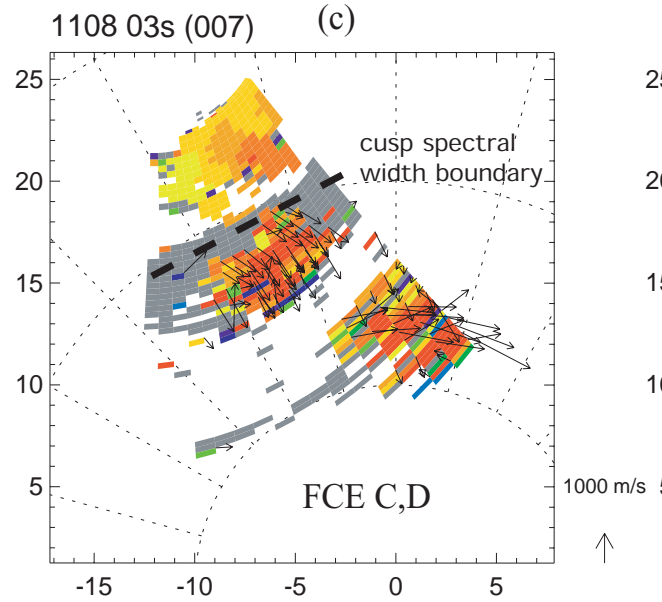

1108 39s (007)

(d)

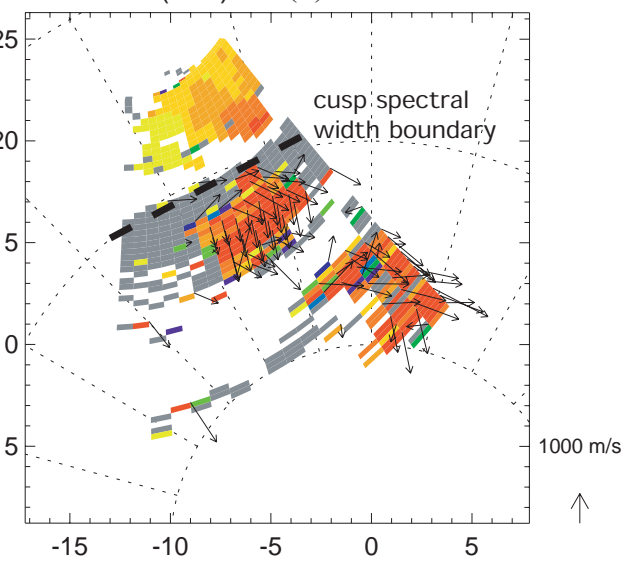

800

600

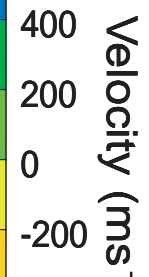

$-400 \stackrel{-1}{-}$

$-600$

$-800$

\section{Ground \\ Scatter}

Fig. 10a-d. Case (c), 7 January, 1998. Scans for the Finland radar showing line-of-sight velocities and beam-swung 2 -D velocity vectors in the same format as Fig. 4. a, b shows the 1105:39 UT and 1106:15 UT scans, imaging flows associated with the group B FTEs in Fig. 9. c, d shows the 1108:03 UT and 1108:39 UT scans associated with
FTEs C and D. The high velocity flows away from the radar (negative velocities) in the western (r.h.s) edge far ranges are the FCEs and lie within the region of 'cusp-like' spectral-widths with the boundary indicated by the dashed line. See Sect. 3(c) in text for further details within the area of 'cusp-like' scatter which lies in the dayside region of the convection cell, in agreement with the previous two case studies. The flow channel appears to be 9-14 MLT $(\sim 1900 \mathrm{~km})$ in azimuthal extent and $73^{\circ}-78^{\circ}$ MLAT $(\sim 550 \mathrm{~km})$ in latitudinal width which agrees with the Provan and Yeoman (1999) observations of pulsed ionospheric flows with wider azimuthal than latitudinal extent. As in the previous case study the overall shape of the convection cells and the location of the reconnection driven flows within them show a degree of variation greater than may be expected from the predictive models (e.g. Cowley and Lockwood, 1992). The region of enhanced flow does not appear to alter appreciably in size over the 1108 to 1116 UT period. Again, an OCFLB has been superimposed and fitted to the cusp spectral width boundary where there is ionospheric scatter. The spectral width boundary does not appear to expand significantly equatorward over time as might be expected if the boundary is a proxy for the OCFLB and the FCEs increase the area of open flux.
The observation time may be too short to observe the redistribution by the convection pattern of open flux from the limited dayside region, created by the transient reconnection, to the entire OCFLB. The OCFLB fitted to the observed spectral-width boundary in Fig. 11c-f lies equatorward of the regions of enhanced flow $\left(>800 \mathrm{~m} \mathrm{~s}^{-1}\right)$ by a couple of degrees MLAT. If the equatorward edge of the reconnection driven enhanced flow is expected to lie on the OCFLB, then the location of the spectral width boundary further equatorward may be the result of the Pcl noise ULF wave ionospheric ducting (Neudegg et al., 1999b; Andre et al., 1999) from the OCFLB at the edge of the cusp.

The three case studies outlined here provide anecdotal evidence of a close association between transient reconnection related to FTEs observed near the magnetopause under IMF 'southward' clock-angle conditions, and impulsive flow channels observed in the polar ionosphere. The flow channels occur on open field lines in the dayside cusp near the open 'throat' of the twin-cell 
convection pattern. The case studies also highlight some of the difficulties in associating FCEs with specific FTEs on a one-to-one basis, necessary for understanding the need for the statistical comparison performed in the following section.

\section{Results of the statistical survey}

As mentioned previously, 87 FTEs were observed by Equator-S when it geomagnetically mapped to the fields-of-view of the Northern Hemisphere SuperDARN radars and 112 FCEs were observed by radars in the polar ionosphere conjugate to the Equator-S spacecraft during the periods of Equator-S magnetopause proximity.

The counting statistics for the comparison of FTEs with FCEs were as follows.

1. $77 \%$ of FTEs (or groups) have a 1:1 association with an FCE (or group)

2. $64 \%$ of FCEs have a $1: 1$ association with an FTE (or group)

3. $23 \%$ of FTEs had no associated FCE

4. $36 \%$ of FCEs had no associated FTEs

The examples in class 3 are negative cases for the hypothesis that FTEs must drive an FCE response in the ionosphere. However it must be remembered that there are inherent uncertainties in the geomagnetic mapping, particularly as most of the FTEs were observed on open field lines in the magnetosheath. The examples in class 4 perhaps demonstrate that FCEs may not only be driven by FTEs but by other causes. More likely is that Equator-S did not observe the FTEs as the reconnection site moved away from it whilst FCEs continued to be observed in the ionosphere as in case study (c). Other enhanced flow velocity features not driven by reconnection may have also been identified as FCEs. A relative timing constraint of FTE and FCE onsets occurring within $3 \mathrm{~min}$ allowed for one-to-one association may mean that some associations were missed.

For a more rigorous statistical comparison a chisquared test was performed on the data using a $2 \times 2$ contingency table, shown in Table 1, where the number of categories were two and the constraint of one degree of freedom was used. The 'trial' length chosen was $15 \mathrm{~min}$ as a representative sample of eight FCEs were found to have an average duration of $8.2 \pm 3.3 \mathrm{~min}$. This trial length would lessen the likelihood of FCEs being counted in two trials although one trial length could possibly contain more than one FTE and as such the trial length is a compromise. The spacecraft and radar data set of $49 \mathrm{~h}$ therefore contains 196 trial intervals. The 'coefficient of contingency' in the range zero to one is a measure of the degree of relationship, association or dependence of the classifications in a contingency table. The coefficient for the uncorrected test and using the 'Yates correction for continuity' (for degrees of freedom $=1$ ) was 0.37 . A similar parameter in the range zero to one, the 'correlation of attributes' is
Table 1. The $\chi^{2}$ contingency table comparing the 'categories', FCE and FTE occurrence, over a total of 196 fifteen minute 'trials'. $\chi^{2}=29.3$ (using the Yates correction for one degree of freedom) indicating association between the categories with $>99.5 \%$ confidence. See Sect. 4 in text for details

\begin{tabular}{lllc}
\hline$\chi^{2}$ & FCE & Nil FCE & Total \\
\hline FTE & 69 & 18 & 87 \\
Nil FTE & 40 & 62 & 109 \\
\hline
\end{tabular}

0.4 in this case. The attributes are the classifications in the contingency table, in this case FTE and FCE. The value for chi-squared was 30.9 and after the Yates correction was applied the value of chi-squared was 29.3. The chi-squared value for a $99.5 \%$ confidence association between the categories using one degree of freedom is 7.88. Therefore both the normal and Yates corrected statistic indicate the FTEs observed by Equator-S and the FCEs observed by the SuperDARN radars to be associated with greater than $99.5 \%$ confidence.

\section{Conclusions}

We have presented the results of the first large-scale survey of the FTE signature representing bursty reconnection at the magnetopause and enhanced plasma velocity flows in the conjugate polar ionosphere. The main conclusions are as follows.

FTEs were observed both in the magnetosheath and inside the magnetosphere. If FTEs represent bursty magnetopause reconnection then that reconnection occurs for a range of IMF clock-angles over $30^{\circ}$ to $330^{\circ}$, predominantly for the $B_{z}$ southward configuration but also for some significant $B_{z}$ northward situations. A strong correspondence has been found between the observation of FTEs in the near magnetopause Equator-S data and FCEs observed by HF radars in the conjugate ionosphere. A one-to-one correspondence between FTEs and FCEs has been shown for individual cases under a variety of magnetopause proximities, FTE locations and occurrence rates. FCEs were associated

Fig. 11a-f. Case (c), 7 January, 1998. Polar ionospheric convection maps using the method of Ruohoniemi and Baker (1998) when both the Finland and Iceland-West radars observed enhanced flow velocities. See Fig. 5 for figure format details. The order of the fit used was 4 , velocities were only spatially and not temporally filtered. The uncertainties for the fit $\chi^{2}$ ranged from 1.9 to 2.6 , see Ruohoniemi and Baker (1998) for details of the technique. a Shows the background flows during 1104 to 1106 UT, before the effect of FTE group B (see Fig. 9). b-f from 1106 to 1116 UT show the development of the flows resulting from FTEs B, C and D. Data are also used from the Kapuskasing and Saskatoon radars to constrain the convection-cell patterns. An extrapolated open-closed field-line boundary (OCFLB) is superimposed and has been fitted to the boundary of 'cusp-like' spectral widths passing through the regions of ionospheric scatter. The flow channels are within the area of 'cusplike' scatter, which lies in the dayside region of the convection cell. See Sect. 3(c) in text for further details 

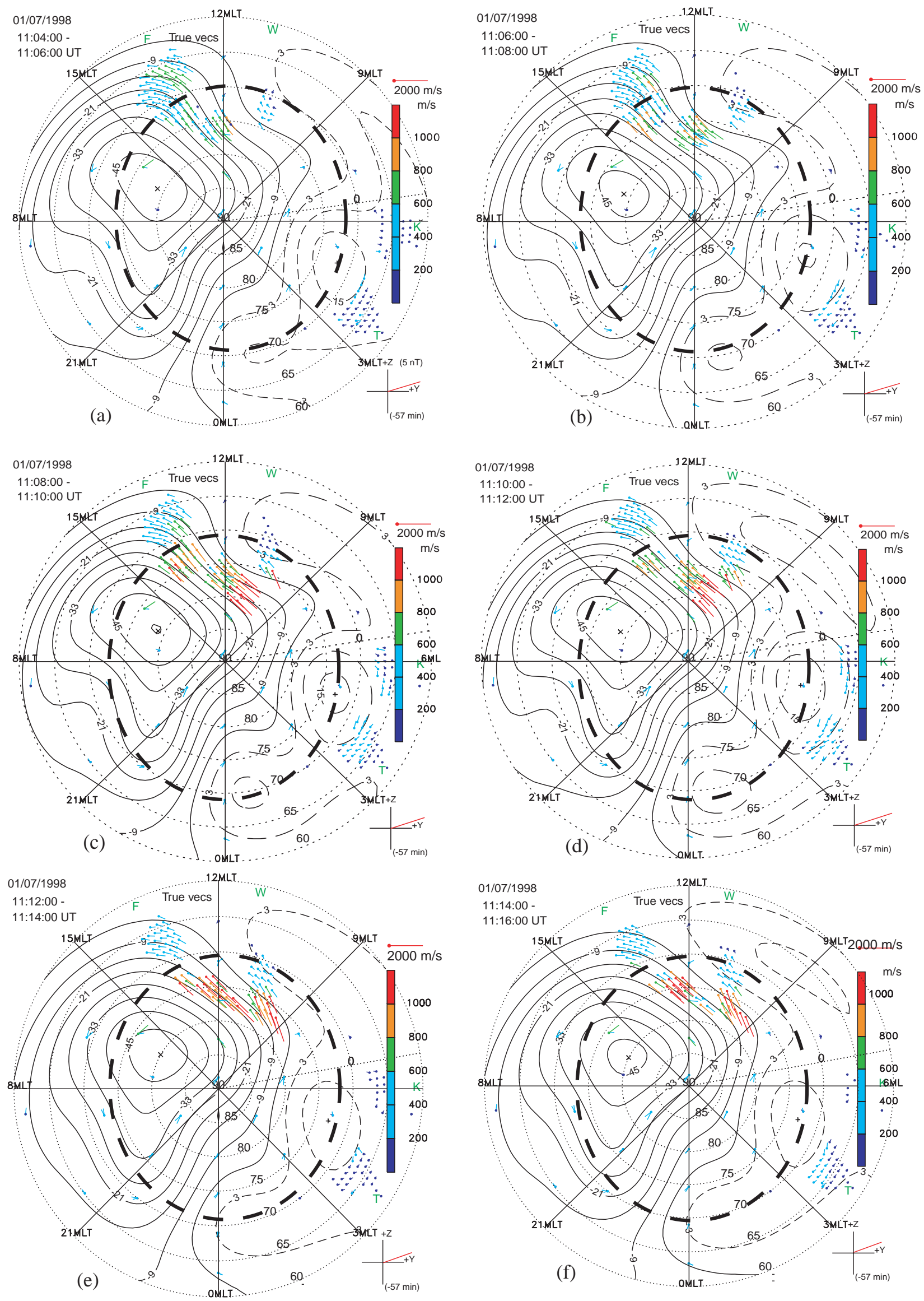
with $\sim 80 \%$ of the FTEs and the two phenomena are shown to be statistically associated with greater than $99 \%$ confidence.

If the inter-FTE temporal spacing is greater than $\sim 5$ min then clearly spaced flow channels can generally be identified and the flow velocity returns to a baseline value afterwards. The ionospheric velocity response to an almost impulsive FTE trigger has a finite rise and decay of the order of $10 \mathrm{~min}$. If FTEs occur more frequently than $\sim 5$ min then the response functions for the individual FTEs convolve into a series of high-speed flows which gradually increase with time. These multiple flow channels sometimes cannot be unambiguously associated with individual features at the magnetopause. However, the average inter-FTE interval was longer than the ionospheric response time and considerably less than $30 \%$ of associations suffer from this problem, as even when the flow responses are convolved the FCE onset is still quite often visible in the l.o.s. velocity of specific range gates.

In the context of polar ionospheric convection patterns the flow channels appear to be consistently located in the dayside open 'throat' of the $B_{z}$ southward pattern, just polewards of the OCFLB. The flows are contained within the region of 'cusp-like' radar spectral widths, the equatorward boundary of which may be a proxy for the OCFLB. Their location agrees with that predicted for the ionospheric effect of transient magnetopause reconnection, adding open flux to the dayside and its subsequent redistribution through the polar ionosphere to achieve a new equilibrium configuration of open and closed flux. The predicted effects of asymmetric IMF $B_{y}$ conditions on flow channels directions have been observed. The variety of modelled convection cell orientations to fit the radar data and the location of the enhanced reconnection driven flows observed within them was more diverse than may have been expected from theoretical predictions. The greater azimuthal than latitudinal dimensions of the flow channels and the flow directions appear to agree with previous observations of pulsed ionospheric flows presumed to be associated with bursty reconnection. Highlatitude ionospheric phenomena previously assumed to be caused by bursty magnetopause reconnection, due to their occurrence under IMF $B_{z}$ southward conditions, may now be more directly associated with magnetopause FTEs if they can be shown to correlate with cusp region flow channels observed by HF radars.

Acknowledgements. We thank the Equator-S staff at the MaxPlanck Institut für Extraterrestrische Physik (MPE), the German Space Operations Centre (GSOC) and T.U. Braunschweig, also the SuperDARN HF radar teams, C.J. Owen (Queen Mary and Westfield College, London) and R. Lepping (NASA/GSFC) for WIND and IMP-8 magnetometer data and SSCWeb for orbit predictions and magnetic field mappings. The Equator-S project was made possible through grant 50 0C 94024 of the German Space Agency (DARA). S. Milan and G. Provan were supported by PPARC grant PPA/G/O/1997/00254 and D. Neudegg by PPARC grant GR/L29767.

Topical Editor G. Chanteur thanks R. Elphic and K.B. Baker for their help in evaluating this paper.

\section{References}

Andre, R., M. Pinnock, and A. S. Rodger, On the SuperDARN autocorrelation function observed in the ionospheric cusp, Geophys. Res. Lett., in press, 1999.

Baker, K. B., J. R. Dudeney, R. A. Greenwald, M. Pinnock, P. T. Newell, A. S. Rodger, N. Mattin, and C.-I. Meng, HF radar signatures of the cusp and low-latitude boundary layer, J. Geophys. Res., 100, 7671, 1995.

Berchem, J., and C. T. Russell, Flux transfer events on the magnetopause: spatial distribution and controlling factors, J. Geophys. Res., 89, 6689, 1984.

Cowley, S. W. H., Excitation of flow in the Earth's magnetosphereionosphere system: observations by incoherent-scatter radar, in Polar cap boundary phenomena eds. A. Egeland, J. Moen, and M. Lockwood, Kluwer, Dordrecht, 127, 1998.

Cowley, S. W. H., Magnetosphere-ionosphere interactions - a tutorial review, in Magnetospheric current systems, eds. S. Ohtani, R. Fujii, M. Hesse, and R. L. Lysak, AGU, Washington D.C., in press, 1999.

Cowley, S. W. H., and M. Lockwood, Excitation and decay of solar wind-driven flows in the magnetosphere-ionosphere system, Ann. Geophysicae, 10, 103, 1992.

Cowley S. W. H., M. P. Freeman, M. Lockwood, and M. F. Smith, The ionospheric signature of flux transfer events, in Cluster: dayside polar cusp, ESA SP-330, ESA Noordwijk, The Netherlands, 105, 1991a.

Cowley S. W. H., J. P. Morelli, and M. Lockwood, Dependence of convective flows and particle precipitation in the high-latitude dayside ionosphere on the $X$ and $Y$ components of the interplanetary magnetic field, J. Geophys. Res., 96, 5557, $1991 \mathrm{~b}$.

Dungey, J. W., Interplanetary magnetic field and the auroral zones, Phys. Rev. Lett., 6, 47, 1961.

Elphic, R. C., M. Lockwood, S. W. H. Cowley, and P. E. Sandholt, Flux transfer events at the magnetopause and in the ionosphere, Geophys. Res. Lett., 17, 2241, 1990.

Farrugia, C. J., D. J. Southwood, and S. W. H. Cowley, Observations of flux transfer events, Adv. Space Res., 8(9), 249, 1988.

Fraser, B. J., Ionospheric duct propagation and Pcl source regions, J. Geophys. Res., 80, 2790, 1975.

Glassmeier, K.-H., and M. Stellmacher, Mapping of flux transfer events to the ionosphere, Adv. Space Res., 18(8), 151, 1996.

Greenwald, R. A., K. B. Baker, J. R. Dudeney, M. Pinnock, T. B. Jones, E. C. Thomas, J.-P. Villain, J.-C. Cerisier, C. Senior, C. Hanuise, R. D. Hunsucker, G. Sofko, J. Koehler, E. Neilsen, R. Pellinen, A. D. M. Walker, N. Sato, and H. Yamagishi, DARN/SuperDARN: a global view of highlatitude convection. Space Sci. Rev., 71, 763, 1995.

Greifinger, C., and P. Greifinger, Theory of hydromagnetic propagation in the ionospheric waveguide, J. Geophys. Res., 73, 7473, 1968.

Haerendel G., G. Paschmann, N. Sckopke, H. Rosenbauer, and P. C. Hedgecock, The frontside boundary layer of the magnetosphere and the problem of reconnection, J. Geophys. Res., 83, 3195, 1978.

Kuo, H., C. T. Russell, and G. Le, Statistical studies of flux transfer events, J. Geophys. Res., 100, 3513, 1995.

Lepping, R. P., et al., The WIND magnetic field investigation, Space Sci. Rev., 71, 207, 1995.

Lockwood, M., Flux transfer events at the dayside magnetopause: transient reconnection or magnetosheath pressure pulses?, J. Geophys. Res., 96, 5497, 1991.

Lockwood, M., and M. N. Wild, On the quasi-periodic nature of magnetopause flux transfer events, J. Geophys. Res., 98, 5935, 1993.

Lockwood, M., and M. A. Hapgood, On the cause of a magnetospheric flux transfer event, J. Geophys. Res., 103, 26 453, 1998.

Lockwood, M., P. E. Sandholt, and S. W. H. Cowley, Dayside auroral activity and magnetic flux transfer from the solar wind, Geophys. Res. Lett., 16, 33, 1989. 
Lockwood, M., P. E. Sandholt, A. D. Farmer, S. W. H. Cowley, B. Lybekk, and V. N. Davda, Auroral and plasma flow transients at magnetic noon, Planet. Space Sci., 38, 973, 1990.

Lockwood, M., W. F. Denig, A. D. Farmer, V. N. Davda, S. W. H. Cowley, and H. Lühr, Ionospheric signatures of pulsed reconnection at the Earth's magnetopause, Nature, 361, 42 4428, 1993.

Lockwood, M., S. W. H. Cowley, M. F. Smith, R. P. Rijnbeek, and R. C. Elphic, The contribution of flux transfer events to convection, Geophys. Res. Lett., 22, 1185, 1995.

McHenry, M. A., and R. C. Clauer, Modeled ground magnetic signatures of flux transfer events, J. Geophys. Res., 92, 11 231, 1987.

McWilliams, K. A., T. K. Yeoman, and G. Provan, A statistical survey of dayside pulsed ionospheric flows as seen by the CUTLASS Finland HF radar, in press Ann. Geophysicae, 2000.

Milan, S. E., T. K. Yeoman, M. Lester, E. C. Thomas, and T. B. Jones, Initial backscatter occurrence statistics from the CUTLASS HF radars, Ann. Geophysicae, 15, 703, 1997.

Milan, S. E., T. K. Yeoman, and M. Lester, The dayside auroral zone as a hard target for coherent HF radars, Geophys. Res. Lett., 25, 3717, 1998.

Milan, S. E., M. Lester, R. A. Greenwald, and G. Sofko, The ionospheric signature of transient dayside reconnection and the associated pulsed convection return flow, Ann. Geophysicae, 17, $1166,1999$.

Neudegg, D. A., B. J. Fraser, F. W. Menk, H. J. Hansen, G. B. Burns, R. J. Morris, and M. J. Underwood, Sources and velocities of Pc1-2 ULF waves at high latitudes, Geophys. Res. Lett., 22, 21, 2965, 1995.

Neudegg, D. A., T. K. Yeoman, S. W. H. Cowley, G. Provan, G. Haerendel, W. Baumjohann, U. Auster, K.-H. Fornacon, E. Georgescu, and C. J. Owen, A flux transfer event observed at the magnetopause by the Equator-S spacecraft and in the ionosphere by the CUTLASS HF radar, Ann. Geophysicae, 17, 707, 1999a.

Neudegg, D. A., B. J. Fraser, F. W. Menk, G. B. Burns, and R. J. Morris, ULF wave propagation in the high-latitude ionospheric waveguide, Adv. Space Res, in press 1999b.

Pinnock, M., A. S. Rodger, J. R. Dudeney, K. B. Baker, R. A. Greenwald, and M. Greenspan, Observations of an enhanced convection channel in the cusp ionosphere, J. Geophys. Res., 98, 3767, 1993.

Pinnock, M., A. S. Rodger, J. R. Dudeney, F. Rich, and K. B. Baker, High spatial and temporal resolution observations of the ionospheric cusp, Ann. Geophysicae, 13, 919, 1995.

Provan, G., and T. K. Yeoman, Statistical observations of the MLT, latitude and size of pulsed ionospheric flows with the CUTLASS Finland radar. Ann. Geophysicae, 17, 855, 1999.

Provan, G., T. K. Yeoman, and S. E. Milan, CUTLASS Finland radar observations of the ionospheric signatures of flux transfer events and the resulting plasma flows, Ann. Geophysicae, 16, 1411,1998
Provan, G., T. K. Yeoman, and S. W. H. Cowley, The influence of the IMF $B_{y}$ component on the location of pulsed flows in the dayside ionosphere observed by an HF radar, Geophys. Res. Lett., 26, 521, 1999.

Rodger, A. S., and M. Pinnock, The ionospheric response to FTEs: the first few minutes, Ann. Geophysicae, 15, 685, 1997.

Rijnbeek, R. P., S. W. H. Cowley, D. J. Southwood, and C. T. Russell, Observations of "reverse polarity" flux transfer events at the Earth's dayside magnetopause, Nature, 300, 23, 1982.

Rijnbeek, R. P., S. W. H. Cowley, D. J. Southwood, and C. T. Russell, A survey of dayside flux transfer events observed by the ISEE-1 and -2 magnetometers, J. Geophys. Res., 89, 786, 1984.

Roelof, E. C., and D. G. Sibeck, Magnetopause shape as a bivariate function of interplanetary magnetic field $B_{z}$ and solar wind dynamic pressure, J. Geophys. Res., 98, 21 421, 1993.

Ruohoniemi, J. M., and R. A. Greenwald, Statistical patterns of high-latitude convection obtained from Goose Bay HF radar observations, J. Geophys. Res., 101, 21 743, 1996.

Ruohoniemi, J. M., and K. B. Baker, Large-scale imaging of highlatitude convection with Super Dual Auroral Radar Network HF radar observations, J. Geophys. Res., 103, 20, 797, 1998.

Ruohoniemi, J. M., R. A. Greenwald, K. B. Baker, J.-P. Villain, C. Hanuise, and J. Kelly, Mapping high-latitude plasma convection with coherent HF radars, J. Geophys. Res., 94, 13 463, 1989.

Russell, C. T., and R. C. Elphic, Initial ISEE magnetometer results: magnetopause observations, Space Sci. Rev., 22, 681, 1978.

Russell, C. T., and R. C. Elphic, ISEE observations of flux transfer events at the dayside magnetopause, Geophys. Res. Lett., 6, 33, 1979.

Saunders, M. A., C. T. Russell, and N. Sckopke, Flux transfer events: scale size and interior structure, Geophys. Res. Lett., 11, $131,1984$.

Sandholt, P .E., A. Egeland, J. A. Holtet, B. Lybekk, K. Svenes, and S. Asheim, Large and small scale dynamics of the polar cusp, J. Geophys. Res., 90, 4407, 1985.

Sonnerup, B. U. Ö., G. Paschmann, I. Papamastorakis, N. Sckopke, G. Haerendel, S. J. Bame, J. R. Asbridge, J. T. Gosling, and C. T. Russell, Evidence for magnetic field reconnection at the earth's magnetopause, J. Geophys. Res., 86, 10 049, 1981.

Southwood, D. J., The ionospheric signature of flux transfer events, J. Geophys. Res., 92, 3207, 1987.

Tsyganenko, N. A., A magnetospheric magnetic field model with a warped tail current sheet, Planet. Space Sci., 37, 5, 1989.

Villain, J. P., R. A. Greenwald, K. B. Baker, and J. M. Ruohoniemi, $\mathrm{HF}$ radar observations of $\mathrm{E}$ region plasma irregularities produced by oblique plasma streaming, J. Geophys. Res., 92, $12327,1987$.

Weimer, D. R., Models of the high-latitude electric potentials derived with a least error fit of spherical harmonic coefficients, J. Geophys. Res., 100, 19 595, 1995. 